\title{
WELCOME TO THE 2008 MRS FALEEXHIBIT
}

The MRS Exhibit, held in conjunction with the 2008 MRS Fall Meeting,

will feature more than 225 international exhibitors from all sectors of the materials science and engineering communities. Meeting attendees are invited to visit the exhibit to learn more about the latest techniques and advances in the swiftly evolving world of materials research directly from the manufacturers, suppliers and developers. Convenient to the technical session rooms and scheduled to complement the program; the MRS Fall Exhibit offers everything you need all under one roof.

\section{HYNES CONVENTION CENTER} SECOND LEVEL DECEMBER 2-4, 2008

EXHIBIT HOURS:

Tuesday, December $2 \ldots \ldots .11: 00 \mathrm{am}-5: 30 \mathrm{pm}$ Wednesday, December 3 .....11:00 am - 5:30 pm Thursday, December 4 ......10:00 am - 1:30 pm Refreshment breaks will be held in the Exhibit Hall on Tuesday and Wednesday afternoon.

\section{MRS FALL EXHIBITORS}

\section{N PLUS INC.}

info@5nplus.com

www.5nplus.com Key Products: II-VI Metals and Compounds; Precursors for Opto-
electronics; Recycling

$5 \mathrm{~N}$ Plus is a manufacturer of high purity metals and compounds used in electronic applications. Metals such as tellurium, cadmium, zinc and selenium are offered in purities from $99.99 \%$ to $99.99999 \%$ as well as all related compounds such as CdTe, CdS, CZT, ZnTe. 5N Plus activities also include recycling of various by-products resulting from our customer's production such as $\mathrm{CdTe}, \mathrm{CZT}$, and $\mathrm{Se}$, thus encouraging sound environmental practices.

\section{A \& N CORPORATION}

sales@ancorp.com

www.ancorp.com

Key Products: Vacuum Components; Vacuum Valves; Vacuum Chambers

A \& N Corporation, manufacturer of high vacuum components since 1965 , offers researchers and laboratories an extensive line of standard high and ultra high vacuum components, as well as custom valves and process chambers. A \& N products are designed to meet or exceed the standards required by industrial and academic users, such as those involved with thin film deposition, surface analysis, laser devices, cryogenics and the aerospace industry. Visit us at www.ancorp.com for more information on all of our high vacuum components.

\section{$A_{2}$ TECHNOLOGIES}

vlopez@a2technologies.com

www.a2technologies.com

Key Products: Handheld FTIR Exoscan; MicroLab; Portable MicroLab

$\mathrm{A}_{2}$ Technologies is the innovator and manufacturer of hand-held portable Fourier Transform Infrared (FT-IR) spectrometers, allowing FTIR analysis to be taken out of the lab and put into the hands of field professionals. $A_{2}$ Technologies' Exoscan hand-held FTIR system is increasingly being deployed for applications where analyzing the condition of a surface is critical. With the ever-expanding use of advanced composites and metals, new tools for nondestructive surface testing are essential, and the high performance Exoscan system is proving ideal for molecular analysis of these materials. In addition to surface analysis, $A_{2}$ Technologies also specializes in portable FTIR for QA/QC, Contamination Analysis, Oil Analysis, and other applications where bringing the analysis to the sample is ideal.
ACCELRYS, INC.

solutions@accelrys.com

www.accelrys.com

Key Products: Materials Studio; Pipeline Pilot

Accelrys develops and commercializes scientific business intelligence software and solutions that help accelerate science for clients in the Life Sciences, Energy, Chemicals, Aerospace, and Consumer Packaged Goods industries. Our solutions are used by biologists, chemists, materials scientists, IT and business professionals to aggregate, analyze, simulate, and visualize scientific data. Our scientifically aware platform and predicative science tools help clients conduct experiments in-silico, make informed decisions, and reduce times for product development. Visit our website at http://accelrys.com/.

\section{ADVANCED DIAMOND TECHNOLOGIES, INC.} www.thindiamond.com

Advanced Diamond Technologies (ADT) is a leader in developing and applying diamond for industrial, electronic, and medical applications. ADT makes NaDiaProbes ${ }^{\mathrm{TM}}$, AFM probes made entirely out of diamond, which last $100 \mathrm{x}$ longer than SiN probes. UNCD Wafers-diamond wafers suitable for research and development of MEMS devices will be exhibited. ADT is a World Economic Forum 2007 Technology Pioneer, a runner-up for the Wall Street Journal's 2006 Technology Innovation Award and a winner of a 2008 R\&D 100 Award.

\section{ADVANCED RESEARCH SYSTEMS, INC.}

\section{ars@arscryo.com}

www.arscryo.com

Key Products: Closed and Open Cycle Cryogenic Systems

ARS offers integrated Displex and Helitran Cryostats for material characterization. Cryostats are available for optical and non-optical (transport, XRD, UHV) applications. The ARS (CCR) Cryocoolers have been redesigned for a temperature range of sub 1.5 to $300 \mathrm{~K}$ or 3 to $800 \mathrm{~K}$. With the lowest vibrations at the sample, it is the cryocooler of choice for laboratory cryogenic applications. Low vibrations systems available for Mossbauer, Optical and Microscopy applications. ARS is introducing the low cost 77K closed cycle cryostats for optical and non-optical experiments as well as the Cryogenic Probe Station with up to 4 probes. ARS manufactures the open and closed cycle cryocoolers with all custom hardware to provide a systems solution for material characterization and sample cooling.

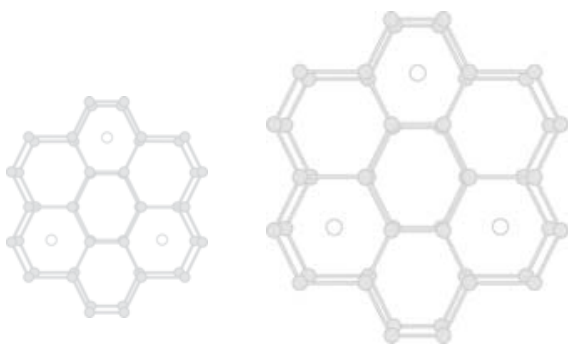


AGILENT TECHNOLOGIES

afm-info@agilent.com

www.agilent.com/find/afm

MRS

AFFILIATE

Key Products: Atomic Force Microscopes, Scanning Probe Microscopes, Scanning Tunneling Microscopes, Particle Analyzers, Nanoindentation Systems, In-situ Mechanical Testing Systems

Agilent's Materials Science Measurement Division is pleased to announce its expansion of instruments for materials research. Agilent now offers nanoindentation systems and in-situ mechanical testing systems to further enable materials research labs with the utmost in measurement platforms. They will unveil their complete line of particle analyzers for determining particle size and zeta potential for inks and pigments, food and beverage, adhesives, coatings, and emulsions and introduce two new high precision atomic force microscopes-the 5600 large stage and 5420 with the exclusive Scanning Microwave Microscopy for electromagnetic materials characterization. We invite you to stop by our booth for discussion of your research or to view a demonstration of these new instruments and techniques designed for material research.

\section{AIST-NT, INC}

info@aist-nt.com

www.aist-nt.com

Key Products: Atomic Force Microscopes, AFM-Raman, SPM Accessories

AIST-NT, Inc. is focused on the innovative research and development of Advanced Integrated Scanning Systems for NanoTechnology. With more than 65 years of combined experience in the Scanning Probe Microscopy industry, AIST-NT, Inc. will be introducing a new line of low noise, fast scanning, extremely stable, AFMs and AFM-NanoRaman ${ }^{\text {TM }}$ Systems. Our new family of products, the latest in SPM imaging technology, is ideal for making quantitative measurements on the nanoscale level and using our new XYZ flexure scanner, we offer significantly faster scanning than most commercially available SPM systems. We also offer from stock delivery of a wide range of SPM accessory products including high quality cantilevers from NIIFP and Micro Masch, plus a wide variety of test gratings and test samples.

\section{AIXTRON AG}

info@aixtron.com

www.aixtron.com

Key Products: MOCVD and CVD Equipment; PECVD and OVPD Equipment; AVD and ALD Equipment

AIXTRON is a leading provider of deposition equipment for the semiconductor industry. The company's technology solutions are used by a diverse range of customers worldwide to build advanced components for electronic and optoelectronic applications based on compound, silicon, or organic semiconductor materials. Such components are used in fiber optic communication systems, wireless and mobile telephony applications, optical and electronic storage devices, computing, signaling and lighting, as well as a range of other leading-edge technologies.

\section{AJA INTERNATIONAL, INC. \\ topgun@ajaint.com \\ www.ajaint.com}

Key Products: Magnetron Sputtering Systems; Magnetron Sputtering Sources; Substrate Holders/Heaters

Sputtering and E-beam Systems for R\&D and Pilot Production. Static and Rotating Magnetron Sputter Sources for HV and UHV, Substrate Holders with Rotation, RF Biasing, Heating and Cooling; Sputter Targets, Microwave, RF and DC Power Supplies, Microwave Components and Plasma Sources, RF Ion/Plasma Sources.

\section{ALFA AESAR, A JOHNSON MATTHEY COMPANY info@alfa.com \\ www.alfa.com}

Key Products: High-Purity Metals; Evaporation Materials; Ceramics Alfa Aesar is a leading manufacturer and supplier of research chemicals, metals and materials. Our product line includes fabricated metals from aluminum to zirconium, provided in a comprehensive range of forms. The full range of over 30,000 products includes inorganic and organic research chemicals, pure elements, alloys, precious metal compounds and catalysts, rare earths, precious metal labware, analytical products and more. Visit our booth for the new High Purity Metals and Materials catalog and more.

\section{AMBIOS TECHNOLOGY, INC. \\ Exhibiting within the NanoLinks Group \\ sales@ambiostech.com}

www.ambiostech.com

Key Products: Surface Profiler; Atomic Force Microscope; White Light Interferometer

Ambios Technology, Inc. manufactures high performance, state-of-the-art, surface metrology equipment. Our product line includes stylus profilometers, non-contact optical profilers, and AFM and SPM instruments. The Ambios line is designed for the researcher who is interested in getting fast repeatable data that is not encumbered by unneeded levels of complication.

\section{AMERICAN CHEMICAL SOCIETY, CHEMINSIGHT cheminsight@acs.org www.cheminsight.org}

Key Products: Scientific Experts; Expert Matching; Consulting \& Expert Witness Chemlnsight is a scientific expert listing and matching service of the American Chemical Society. Experts in the sciences are invited to register their profile on our website, www.Chemlnsight.org. Professionals and firms requiring scientific expertise to solve problems can search for free online. A fee-based custom Expert Matching Service is also available. We promote you so you gain contacts and consulting engagements.

\section{AMERICAN CHEMICAL SOCIETY, PUBLICATIONS \\ help@acs.org \\ pubs.acs.org}

Key Products: Journals (Web and Print); Magazines; Books

ACS Publications is introducing ACS Applied Materials \& Interfaces, an international forum for applied materials science and engineering, in January 2009. Other ACS journals include Chemistry of Materials - \#1 in citations $(43,179)$ in Materials Science with a high Impact Factor of 4.883; Crystal Growth \& Design-\#1 in Impact Factor (4.046) in Crystallography; Nano Letters-\#1 in total citations $(26,246)$; ACS Nano; and The Journal of Physical Chemistry A, B and C, and Langmuir.

\section{AMERICAN INSTITUTE OF PHYSICS \\ mktg@aip.org \\ www.aip.org}

Key Products: Journals; Conference Proceedings; Complete Publishing Services

Contributors to AIP journals have an open-access publishing option, Autho Select, for immediate free distribution worldwide. Readers of AIP journals have options, too: RSS feeds are available by topic or title, AIP Article Packs provide a package of downloads from all journals at highly discounted rates, and new Web 2.0 tools allow more interaction with content. Visit the AIP booth to learn more-and discover the new, complete Physics Today online archive as well. 


\section{AMERICAN PHYSICAL SOCIETY \\ assocpub@aps.org \\ www.aps.org}

Key Products: Physics Journals; Online Journals; PROLA (Online Archive)

The American Physical Society is the publisher of the world's most prestigious and widely-read physics research journals: Physical Review $A, B, C, D, E$, Physical Review Letters, Reviews of Modern Physics, PROLA (Physical Review Online Archive), PR-Special Topics-Accelerators and Beams, PR-Special Topics-Physics Education Research and PR Focus. PROLA's fully searchable content and full-text articles includes everything published by APS back to 1893 .

\section{ANASYS INSTRUMENTS CORP. \\ roshan@anasysinstruments.com \\ www.anasysinstruments.com}

\section{Key Products: Nano-thermal Analysis; VESTA}

Our breakthrough and award-winning (R\&D100/MICRO-NANO25) thermal probe technology enables AFM users to heat local regions sub- $100 \mathrm{~nm}$ in diameter and the accompanying hardware/software enables our customers to measure local thermal properties. Our nano-TA product (comprising hardware, software and probes) enables AFM users in polymers, materials science and pharmaceuticals to measure phase transitions of local regions so as to get local Tg and Tm information. We have a stand-alone product called the VESTA which is a push-button easy-to-use product for thermal analysts (i.e., DSC/DMA/TMA users) who are interested to use localized thermal analysis techniques but do not want to deal with the complexity of an AFM.

\section{ANDEEN-HAGERLING, INC.}

\section{info@andeen-hagerling.com}

www.andeen-hagerling.com

Key Products: Capacitance/Loss Bridges; Precision Reference Capacitors

Manufacturers of the most precise capacitance/loss bridges and capacitance standards available commercially. Bridges are fully automatic and can resolve measurements to sub-attofarad levels. Operation at fixed or variable frequencies $(50 \mathrm{~Hz}$ to $20 \mathrm{KHz})$. Loss (dissipation factor) measured down to $1.5 \times 10^{-8} \tan \delta$. A-H bridges are ideal for many capacitance-based, precision sensor applications. AH capacitance standards available from $0.1 \mathrm{pF}$ to $115 \mathrm{pF}$. Standards have stability $<0.3 \mathrm{ppm} /$ year, temperature coefficient of $.01 \mathrm{ppm} / \mathrm{deg} \mathrm{C}$, and are NIST traceable to an accuracy of 2 ppm.

\section{ANFATEC INSTRUMENTS AG \\ mailbox@anfatec.de}

www.anfatec.de

Key Products: AFM and STM; LockIn Amplifiers; SPM Controllers

Anfatec Instruments AG is an established German company producing and distributing instrumentation for surface science. The product range implies scanning probe instruments like AFM (Atomic Force Microscopes) systems and STM (Scanning Tunneling Microscopes); PC-based, affordable SPM controllers as well as parts and accessories for scanning probe microscopes. The product range is completed with digital Lockln amplifiers. Anfatec is the German distributor for MikroMasch and other cantilever and grating suppliers.

\section{ANGSTROM SCIENCES \\ info@angstromsciences.com \\ www.angstromsciences.com}

Key Products: Sputter Sources; PVD Materials; Magnetron Sputtering Cathodes

Angstrom Sciences designs, engineers and manufactures high-performance magnetron sputtering sources and materials for R\&D and production applications. The patented Angstrom Advantage ${ }^{\mathrm{TM}}$ design in our circular, linear, and cylindrical magnetrons provides the unique combination of high target utilization and deposition rates with uncompromised film. In addition, Angstrom Sciences offers a comprehensive selection of high-purity vacuum-deposition materials. Using a variety of specialized processes, we provide the kind of homogenous, fine-grained, high-density materials that conform to the strictest quality control.

\section{ANGSTROM SUN TECHNOLOGIES, INC. \\ info@angstec.com \\ www.angstec.com}

Key Products: Spectroscopic Ellipsometer; Microspectrophotometer; Thin Film Thickness Measurement Tools; Reflectometer

Angstrom Sun Technologies, Inc. provides advanced but affordable TFProbe series optical instruments for characterizing film/coating thickness, surface/ Interface, optical Constants N \& K and other optical properties: 1) Automatic Variable Angle Spectroscopic Ellipsometer; 2) Desktop Film Thickness Mapping System; 3) Microspectrophotometer and film thickness measurement system for MEMS and patterned wafer with a sampling region as small as $1 \mu \mathrm{m}$; 4) Simple, low cost and easy-to-use thin film thickness measurement station; 5) Digital cameras eyepiece for various microscopes and vision system; 6) Software for thin film and digital imaging analysis; and 7) Advanced analytical service for film thickness and optical constants.

\section{ANNEALSYS}

info@annealsys.com

www.annealsys.com

Key Products: RTP; LPCVD; MOCVD

Annealsys manufactures Rapid Thermal Processing and Chemical Vapor Deposition equipment for research and development and production applications. RTP systems are available from 2- to 8-inch wafer capability for RTP and RTCVD processes. Cold wall chamber, lamp furnace, high temperature $\left(1400^{\circ} \mathrm{C}\right)$ and high vacuum capability are the main features. R\&D CVD systems: 2-inch RTP-MOCVD tool and 4-inch MOCVD tool dedicated to oxide and metal deposition and 4-inch LPCVD furnace are available. Worldwide sales and service support.

\section{APPLIED NANOSTRUCTURES, INC.}

info@appnano.com

www.appnano.com

Key Products: SPM and AFM Probes; Nano Pores; MEMS Devices

Located in the heart of Silicon Valley, California, USA, Applied NanoStructures mission is to provide high quality AFM probes for all applications. Typical tip radius of curvature is 5-6 $\mathrm{nm}$. MFM and EFM probes give superior performance due to specialized metal coating techniques. A wafer of probes contains about $7 \%$ more probes making it the best combination of probe and quality. Applied NanoStructures leverages its in-house clean room to invent new technologies, to provide complete solution to their customers for standard as well as exclusive AFM probes from design to nanofabrication and to expand the product line for research in nanotechnology. 
APPLIED SURFACE TECHNOLOGIES

co2clean@co2clean.com

www.co2clean.com

Key Products: $\mathrm{CO}_{2}$ Snow Jet; Surface Cleaning

The $\mathrm{CO}_{2}$ Snow Jet cleaning process will be demonstrated. The Snow Jet cleaning process is a simple surface cleaning process that removes particles of all sizes (down to 0.03 microns) and also organic residues. The process works well for many substrates, wafers, thin films, optics, vacuum parts, analytical samples (AFM), etc. We will show new data on cleaning AFM calibration standards. The Snow Jet process is, nondestructively, residue-free with no environmental limitations. Bring samples for a demo!

\section{ARKALON CHEMICAL TECHNOLOGIES, LLC \\ contact@arkalonllc.com \\ www.arkalonllc.com}

Key Products: Custom Chemical Manufacturing Services; Organometallics; Reactive Monomers and Polymer Additives

Arkalon Chemical Technologies, LLC is a dynamic, young company dedicated to helping its customers develop robust supply chains for their chemical requirements. Arkalon is a full service chemical supplier supporting its customers with capabilities in custom synthesis, process development, and full scale production. We are staffed by business and technical professionals with significant industry experience. We work collaboratively with customers to define needs, evolve specifications and develop timelines for supply. All our work is undertaken with strict attention to confidentiality to ensure that our customers' intellectual property remains protected.

\section{ARRADIANCE, INC.}

marketing@arradiance.com

www.arradiance.com

Key Products: Engineered Thin Films; Advanced Technology Microchannel Plates; Specialty Deposition Equipment

Arradiance is at the forefront of Advanced Technology Microchannel Plate (AT-MCP) and Channel Electron Multiplier (CEM) development. Using state-ofthe-art material science and engineered thin-film fabrication techniques, Arradiance has demonstrated Microchannel Plates with up to 10X the gain of conventional reduced lead glass plates without increasing noise or sacrificing device lifetime. Our MCP technology provides a more repeatable and uniform amplifier for imaging and detection applications. Our specialty deposition equipment can process small, two sided substrates quickly and efficiently.

\section{ASEMBLON, INC}

sales@asemblon.com

www.asemblon.com

Key Products: Alkane Thiols; Functionalized Gold Slides; Surface Engineering Consulting

Asemblon, Inc. is the leader in self-assembled monolayers with 30 years of experience in thiol-on-gold surface assembly and science. Asemblon's compounds are the purest (99+\%). Our new products and services include: 1) Noble metal substrates, 2) Surface functionalization, 3) Surface testing with ESCA (XPS) and other methodologies, 4) Consultation on surface modification, 5) Custom synthesis of thiols, 6) Wide range of large and small order quantities of chemistry, and 7) Educational kits for high school and above.

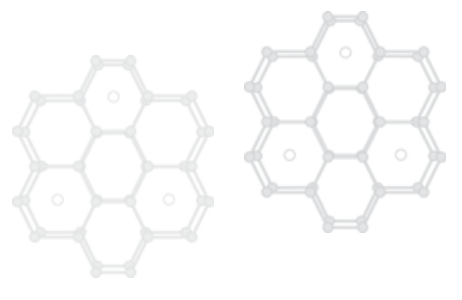

ASYLUM RESEARCH

sales@AsylumResearch.com

www.AsylumResearch.com

Key Products: Atomic Force Microscopes; Scanning Probe Microscopes Asylum Research manufactures advanced AFMs for materials, life and nanoscience applications. The MFP-3D ${ }^{\mathrm{TM}}$ AFM, available in both bio and materials configurations, has set the standard for unprecedented precision, accuracy and high resolution imaging with sensored closed loop operation in all three axes. Asylum continues to lead the industry with ground-breaking technical innovations such as Dual $\mathrm{AC}^{\mathrm{TM}}$ Mode for characterizing frequency-dependent material properties; quantitative nanoindenting; and the high voltage, crosstalk free Piezo Force Module. Band Excitation, a 2008 R\&D 100 award winner, allows rapid probing of energy dissipation.

\section{ATRP SOLUTIONS}

information@atrpsolutions.com

www.atrpsolutions.com

Key Products: Systematic Libraries; Contract Research; Ligands

Building Polymers for Tomorrow's Products. Block copolymers with hydrophilic and hydrophobic segments can self-assemble into nano-scale architectures ranging from simple micelles to complex gyroids. Recent studies on block copolymer self-assembly have found that nano-scale architecture is highly dependent on chain length of each block and composition of each block. ATRP Solutions, Inc. provides systematic libraries of block copolymers which allow researchers to establish relationships between block copolymer composition and self-assembled nano-scale architecture.

\section{ATTOCUBE SYSTEMS AG}

Exhibiting within the NanoLinks Group

info@attocube.com

www.attocube.com

Key Products: Nanopositioning Systems; Low Temperature Microscope; SPM Controller

attocube systems AG offers a wide range of high-precision nanopositioning systems, easy-to-use scanning probe microscopes and probe stations. Temperatures down to $10 \mathrm{mK}$, high magnetic fields up to $28 \mathrm{~T}$, and ultra-high vacuum conditions - the nanopositioners solve experimental tasks at the cutting edge. attocube's instruments enable users to analyze samples in various ways with atomic precision, even at Milli-Kelvin-temperatures.

\section{BADEN-WÜRTTEMBERG INTERNATIONAL info@bw-wfk.de \\ www.bw-i.de}

Materials Research in Baden-Württemberg: Germany at its best! Baden-Württemberg, the German Southwest, offers the highest density of research institutions and universities in Germany. Their worldwide reputation as centers of excellence is well-deserved. Among them are those exhibiting at the 2008 MRS Fall Meeting. Visit our booth to meet representatives from:

- Karlsruhe Institute of Technology (KIT)-The Cooperation of Universität Karlsruhe (TH) and Forschungszentrum Karlsruhe $\mathrm{GmbH}$

- Karlsruhe University of Applied Sciences-Institute of Computational Engineering

- Fraunhofer Institute for Chemical Technology (ICT)

- Fraunhofer Institute for Mechanics of Materials (IWM)

- Max-Planck-Institute for Metals Research 
BALAZS ANALYTICAL SERVICES

\section{info@balazs.com}

www.balazs.com

Key Products: Contamination Analysis; Thin-Film \& Wafer Analysis; Solar/Photovoltaic/Semiconductor Troubleshooting

Balazs Analytical Services operates ISO 17025 accredited laboratories that identify, analyze, and resolve contamination issues for semiconductor and other high-tech industries. Balazs analyzes water, air, chemicals, process gases, components, and wafers with industry experts available to identify and track contamination to their source using: High Resolution ICP-MS, ICP-OES, GD-OES, XRF, IC, SEM-EDS, LA-ICP-MS, VPD, GC, GC-MS, FTIR, Raman, wafer outgassing, air and gas sampling, and thin film analysis.

\section{BLUE WAVE SEMICONDUCTORS, INC.}

\section{info@bluewavesemi.com}

www.bluewavesemi.com

Key Products: Substrate Heaters; Thin Films; Thin Film CVD

Bluewave Semiconductors, Inc. (BWS) is proud to present its line of wafer/ substrate heating products for controlled and precise process heating which is essential in thin film synthesis in device manufacturing, and research and development. BWS provides innovative wafer/substrate heating assemblies including the electronics. The heater product lines are available for use in vacuum $\left(\leq 5 \times 10^{-4}\right.$ torr) and other gaseous ambient. These heaters have been proven by our valued customers in basic research laboratories as well as in manufacturing. Backed by years of experience and expertise, BWS has the unique ability to extend technical support and work closely with customers to provide system solutions and custom designs by request. Additional product lines include radiation hard transparent coatings and low cost oxide UV photodetectors. BWS has also developed a novel low cost PVD method for growing epitaxial aluminum nitride and AIN alloys for LED III-nitride and RF MEMS technology.

\section{BRINKMANN INSTRUMENTS, INC.}

See Metrohm USA, Inc.

\section{BRUKER AXS INC.}

\section{info@bruker-axs.com}

www.bruker-axs.com

MRS

CORPORATE

AFFILIATE

Key Products: X-Ray Diffraction Instruments; Detectors; Microanalysis Instruments

Bruker AXS specializes in high-end X-ray diffraction solutions performing a wealth of applications in materials analysis. Our technology is used to investigate complex samples ranging from wafers, thin films, and powders to amorphous materials. We are the market leader in XRD, offering the largest, highest quality portfolio of cutting edge diffraction components and software. Our products include the D8 product line, Super Speed Solutions, NanoStar, Multex Area, Leptos, NanoFit and Topas.

\section{BRUMLEY SOUTH, INC.}

info@brumleysouth.com

www.brumleysouth.com

Key Products: Used Semiconductor Equipment; Equipment for Nanotechnology; High-tech Equipment and Service

Brumley South, Inc. offers complete metrology and robotic services and provides remanufactured equipment to the research community. We specialize in designing, installing and supporting upgrades for ADE, Flexus, KLA-Tencor Surfscan, Promterix, and Nanometrics tools. We also support Wafer Handling Robots, provide NIST Traceable Latex Sphere Calibration Standards, Particle Deposition Systems, and Semiconductor parts and service.
CAMBRIDGE NANOTECH INC.

info@cambridgenanotech.com

www.cambridgenanotech.com

Key Products: ALD Systems; Savannah; Phoenix

Cambridge NanoTech focuses on simplifying the science of atomic layer deposition (ALD) solutions for customers worldwide-from universities to the largest corporations-by delivering comprehensive services and versatile, turnkey systems that are accessible, affordable and accurate to the atomic scale. With unparalleled support, Cambridge NanoTech experts collaborate with customers to apply thin film techniques to unique coating challenges, acting as a catalyst for new applications worldwide. Cambridge NanoTech grew directly out of the foremost ALD research group in the world-the Gordon Lab at Harvard University. It was founded in 2003. With over 100 systems shipped, Cambridge NanoTech is the leading ALD supplier to Research and Industry worldwide.

\section{CAMBRIDGE UNIVERSITY PRESS \\ information@cup.org \\ www.cambridge.org/us}

Key Products: Books; Journals; CD-ROMs

Please stop by the Cambridge University Press booth to peruse the latest in materials science, including Volume 2 of Crystallization of Polymers by Leo Mandelkern; Physical Properties of Polymers by James Mark et al.; Thin Film Materials by Ben Freund and Subra Suresh; Some Modern Methods of Organic Synthesis by William Carruthers and lain Coldham; The Art of Molecular Dynamics Simulation by Dennis Rapaport; and Electronic Structure by Richard Martin. Buy now and enjoy a special $20 \%$ discount!

\section{CAMECA INSTRUMENTS, INC.}

sales.usa@cameca.com

www.cameca.com

Key Products: SIMS, Electron Probes, Atom Probes

CAMECA manufactures high-performance quantitative analytical tools for materials research at the micron, nano and atomic scales. We invite you to our booth to see how our magnetic sector and quadrupole SIMS, and 3D Atom Probe can serve your ultra-shallow, ultra-thin, ultra-fine feature measurement needs for traditional and innovative (PV, nano, multilayer) characterization. This year, we highlight NanoSIMS-50, IMS 7f, 4550 SIMS, and LA-WATAP laserassisted tomographic atom probe, as well as SX100 EPMA, multi-layer and trace element instrument.

\section{CAPOVANI BROTHERS INC.}

\section{cbi@capovani.com}

www.capovani.com

Key Products: Used Semiconductor Equipment; High-technology Equipment; Equipment for Nanotechnology

Capovani Brothers Inc. buys and sells semiconductor manufacturing and related high technology equipment in the MEMS, nanotechnology, semiconductor and compound semiconductor industries. All equipment is sold refurbished and warranted. For twenty years we have succeeded in our mission of providing quality used equipment at a great value. Our entire inventory is located in our facility in upstate New York's "Tech Valley" and can be viewed on our website at www.capovani.com. Site visits are always welcome!
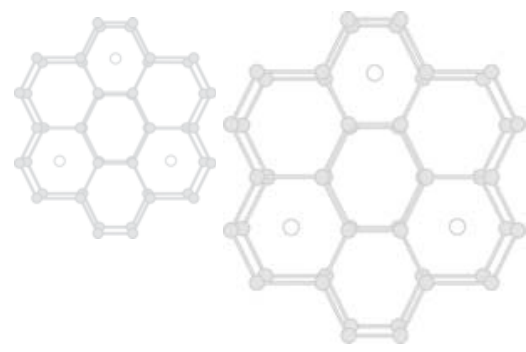
CARL ZEISS SMT INC.

info-usa@smt.zeiss.com

www.smt.zeiss.com/nts

Key Products: Electron Microscopes; FlB

Carl Zeiss SMT's Nano Technology Systems Division offers industry leading analytical $\mathrm{EVO}^{\otimes} \mathrm{SEMs}$, a complete range of ultra high resolution GEMINI ${ }^{\circledR}$ FESEMs, energy filtering TEMs and FIB workstations, featuring the NVision, the only tool capable of simultaneous imaging and milling. Its newly invented helium ion microscope, ORION ${ }^{\mathrm{TM}}$, provides high resolution images and contrast mechanisms which are complimentary to the traditional SEM or FIB. SMT solutions are perfect for nanotechnology applications in semiconductor technology, materials research and the life sciences.

\section{CEM CORPORATION}

info@cem.com

www.cem.com

Key Products: Discover ${ }^{\oplus}$ Microwave Synthesizer; MARS ${ }^{\mathrm{TM}}$ Microwave Synthesizer; Explorer ${ }^{\oplus}$ Automated Microwave Synthesizer

CEM is a leading global provider of microwave synthesis systems that are used in a variety of applications, including nanomaterial and polymer synthesis. In both areas, CEM Systems have been proven to both reduce reaction times and generate a more uniform product. The Discover ${ }^{\circledR}$ platform offers unmatched flexibility with a wide variety of options including automation, gaseous reagent addition, pressurized or atmospheric reaction capability, low-temperature synthesis, and more, plus award-winning technical service and applications support.

\section{CENTER FOR TRIBOLOGY, INC. (CETR, INC.) \\ sales@cetr.com \\ www.cetr.com}

Key Products: Universal Nano+Micro+Macro Materials Testers

CETR is a world leading manufacturer of nano, micro and macro precision mechanical testers for coatings, thin films and bulk materials, with measurements of adhesion, delamination, scratch-resistance, nano- and micro- hardness, elastic modulus, friction, reciprocating and rotary wear, fatigue, elasticity, plasticity and other mechanical properties, including in controlled temperature $(-25 \mathrm{C}$ to $+1,000 \mathrm{C})$, humidity or vacuum, for biomedical, microelectronics, data storage and other industries, as well as for basic materials research on nano and micro levels.

\section{CERAC, INC.}

See Williams Advanced Materials

\section{CERAMTEC NORTH AMERICA CORP. \\ sales@ceramtec.com \\ www2.ceramtec.com}

Key Products: Hermetic Feedthroughs; Multipin and Coaxial Connectors; Viewports/Windows

CeramTec North America designs and manufactures ceramic-to-metal and glass-ceramic hermetically sealed electrical and optical components. These products include: feedthroughs, multipin connectors (Circular and Sub D Type), coaxial connectors, viewports/windows, thermocouples, isolators, baseplate feedthroughs, cables and custom assemblies. CeramTec has more than 55 years of experience behind our hermetically sealed components, which include both standard and CUSTOM designs for use in vacuum, ultrahigh vacuum, high-pressure, cryogenic and high-temperature applications. ISO 9001:2000 quality system certified.

\section{CHEAP TUBES, INC \\ sales@cheaptubes.com \\ www.cheaptubes.com}

Key Products: Single-walled Nanotubes; Multi-walled Nanotubes; Functionalized Nanotubes; Short Nanotubes

We are committed to supplying the nanotechnology community with a vast supply of high quality Carbon Nanotubes at a fraction of our competitors' prices. Whether you're an independent researcher or a large volume user, Cheap Tubes' customers save $50 \%$ or more on their CNT orders. Call us for high purity MWNTs, SWNTs, $\mathrm{OH}$ and $\mathrm{COOH}$ functionalized CNTs, large volume industrial grade CNTs and Short CNTs. Please visit www.cheaptubes.com/ cntpricelist.htm today and compare prices and quality.

\section{CHEMAT TECHNOLOGY, INC. \\ marketing@chemat.com}

www.chemat.com

Key Products: Spin Coater; Coating Equipment; Chemical Precursors

Chemat Technology, Inc. is one of the leading worldwide resources for advanced materials processing. Chemical products offered, in research and bulk quantities, include: high purity of metal alkoxides, dialkylamides, organo-polymers, high surface area powders, colloidal solutions and functional solutions for the sol-gel and/or CVD processes. As the manufacturer of the least expensive quality spincoater in the world, Chemat also designs and distributes thin film coating equipment, fiber drawing machine, rotary evaporators, microscopes and diverse laboratory instruments.

\section{COMSOL, INC.}

info@comsol.com

www.comsol.com

Key Products: COMSOL Multiphysics

COMSOL provides $\mathrm{COMSOL}_{\text {Multiphysics }}{ }^{\oplus}$, a modeling package for the simulation of any physical process you can describe with partial differential equations (PDEs). To deal with the increasing demand for realistic representations of the world around us, you can easily model systems of coupled physics phenomena. Our state-of-the-art solvers, ease of use, and unprecedented flexibility make COMSOL Multiphysics the ideal modeling and simulation software for research, product development, and education.

\section{CONCENTRIS GMBH}

info@concentris.ch www.concentris.ch

Key Products: Cantilever Sensor Platforms for Gas and Liquid Analysis; Cantilever Functionalization

Concentris $\mathrm{GmbH}$ (Basel, Switzerland) provides high-performance research instruments based on nanomechanical cantilever sensors. Concentris' Cantisens ${ }^{\circledast}$ products give access to a wide range of applications, such as the real-time study of surface-related phenomena. The Cantisens ${ }^{\circledast}$ Research platform has been designed for scientific research and application development in the fields of biological, chemical, medical or materials research in liquids or gas. It features cantilever arrays with eight customizable cantilever sensors, integrated sample handling and precise temperature control.

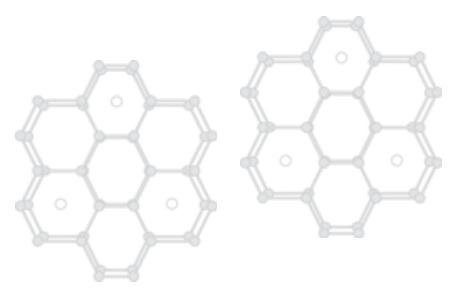


CRYSTALMAKER SOFTWARE LTD.

\section{info@crystalmaker.com}

www.crystalmaker.com

Key Products: CrystalMaker 8.1 for Mac; CrystalMaker 2.1 for Windows; SingleCrystal 1.1 for Windows; CrystalDiffract 1.2 for Windows

CrystalMaker Software Ltd. develops software for working with crystalline materials and their diffraction patterns, including the award-winning CrystalMaker $^{\circledast}$ (interactive structures visualization) with its real-time photorealistic graphics. This works seamlessly with our other products: CrystalDiffract $^{\mathrm{TM}}$ ( $\mathrm{x}$-ray and neutron powder diffraction) and SingleCrystal ${ }^{\mathrm{TM}}$ (electron diffraction and stereographic projections). All products feature elegant, easy-to-use interfaces plus cross-platform compatibility for Windows XP/Vista and Mac OS X (PowerPC/Intel).

\section{CSM INSTRUMENTS INC}

Exhibiting within the NanoLinks Group

usinfo@csm-instruments.com

www.csm-instruments.com

Key Products: Scratch Testers; Indentation Testers; Tribology

CSM Instruments is leader in the development of instruments for advanced materials testing for over thirty years. Our products include Hardness Testers, Scratch Testers, and Tribometers of varying load ranges. 3D-imaging options are available with the ConScan or AFM objective. CSM manufactures standalone instruments as well as testing modules that can be configured alone or combined together on a testing platform for a single instrument capable of multiple analysis modes. We also offer full contract testing services.

\section{CVD EQUIPMENT CORPORATION \\ info@cvdequipment.com}

www.cvdequipment.com

Key Products: CVD Equipment; Carbon Nano Tube/Wire Synthesis; Gas Delivery Equipment; Liquid/Vapor Delivery Equipment

CVD Equipment Corporation is in its $26^{\text {th }}$ year of designing, developing and manufacturing semiconductor processing equipment and quartzware. CVD Equipment Corporation is a leading manufacturer of critical APCVD, LPCVD, UHVCVD, MOCVD, LPE, VPE, HVPE and RTP products and services for the Semiconductor, Solar, Opto-electronic, Wireless Telecommunications and MEMS markets. Our First Nano division manufactures turnkey CVD processing systems for the production of single wall carbon nanotubes (SWNT), multiwall carbon nanotubes (MWNT), various Nanowires, Silicon Germanium (SiGe), Second Generation PV materials and Graphine.

\section{DCA INSTRUMENTS, INC.}

dcausa@optonline.net

www.dca.fi

Key Products: UHV Deposition Systems; MBE Components; PVD Systems

DCA Instruments specializes in the design and manufacture of high-quality UHV deposition systems, offering standard systems for the following deposition techniques: III-V, II-VI, CMT-MBE, metal MBE, UHV sputtering, UHV laser ablation, and UHV CVD. DCA Instruments also offers a wide range of MBE components which are retrofittable to the majority of existing systems. Components include effusion cells, soft-action magnetically driven linear shutters, a 'zero-wobble' substrate manipulator and a self-regulating mercury source.

\author{
DELONG AMERICA INC. \\ info@lv-em.com \\ www.lv-em.com
}

Key Products: Benchtop Combined TEM, SEM and STEM

Delong provides the materials scientist with a one-of-a-kind imaging solution the Benchtop LVEM5. The system employs a 5 kV FEG source that delivers best-in-class contrast at 2 nanometer resolution and is ideal for imaging polymers, biomaterials and nanostructures. The LVEM5 has 3 imaging modes (TEM, SEM, STEM) so that both internal structure and surface detail can be studied-with effortless transitioning between modes. Image acquisition, analysis, sharing and archiving are supported by a Olmaging $2 \mathrm{~K} \times 2 \mathrm{~K}$ cooled CCD camera and software. Delong has a well-earned reputation as a quality manufacturer of electron optics, vacuum components and other precision engineering solutions. With the LVEM5, Delong brings these strengths, plus outstanding customer support, directly to the materials scientist's lab bench.

DELTANU, INC.

sales@deltanu.com

www.deltanu.com

Key Products: Raman Microscopes; Bench-top Raman; Portable/Hand-held Raman; Palm-sized Raman; Raman Accessories

DeltaNu manufactures Raman spectrometers and accessories for academics, industry, and law enforcement. The ExamineR Raman microscope has outstanding imaging and spectral characteristics. The Advantage Series benchtop systems feature four different wavelengths; $532 \mathrm{~nm}, 633 \mathrm{~nm}, 785 \mathrm{~nm}$, and $1064 \mathrm{~nm}$. The Inspector Raman and RockHound are handheld spectrometers used for field work. The new $11 \mathrm{oz}$. ReporteR uses preprogrammed libraries to identify unknown substances. DeltaNu also offers a variety of accessories for liquids, solids, and microscopy.

\section{DENTON VACUUM, LLC}

info@dentonvacuum.com

www.dentonvacuum.com

Key Products: Sample Preparation Tools; High Vacuum Carbon Evaporators; Thin Film Deposition Systems

Denton Vacuum is a leading U.S. manufacturer with over four decades of leadership in design, manufacture and support of thin film deposition systems for science and industry. Reliability and support are assured-spare parts are always available for rapid delivery. We carry a full line of EM systems and accessories. Stop by to see our newest generation of sample preparation systems. Ask about our special show promotion. Quality products, dependable customer service and a commitment to your satisfaction and success.

\section{DIAMOND WIRE TECHNOLOGY, LLC \\ info@diamondwiretech.com}

www.diamondwiretech.com

Key Products: Diamond Impregnated Wire; Multi-Wire Saws; Single Wire Saws

Diamond Wire Technology-the World's Largest and Oldest producer of Diamond Wire and Diamond Wire Saws. Diamond Wire produces the smallest kerf, highest throughput and precision quality surface finishes for all wafering, cutting needs. Slurry saws can be converted to Diamond Wire, a cleaner, faster process that produces the highest finishes, increases production and lowers cost. Multi-Wire Saws, Single Wire Saws and Custom Saws are designed for a variety of applications. Enhanced Performance Through Innovation. 
DIGITAL SURF SARL

contact@digitalsurf.fr

www.digitalsurf.com

Key Products: Surface Imaging and Analysis Software for Microscopes and Profilometers

Digital Surf's Mountains Technology provides surface visualization and analysis for all types of microscopes and profilometers, including SPM and confocal. It integrates the latest standards and methods, opening up new horizons thanks to continuous innovation. Mountains is already adopted by many leading instrument manufacturers and used in thousands of laboratories and industrial facilities worldwide. Today Mountains has taken a leap forward into the 4th dimension and analyses surface evolution.

\section{DR. EBERL MBE-KOMPONENTEN GMBH}

info@mbe-components.com

www.mbe-components.com

Key Products: Effusion Cells; E-Beam Evaporators; Cracker Sources

Dr. Eberl MBE-Komponenten is a leading manufacturer of thin film deposition equipment for molecular beam epitaxy, surface science and other UHV applications. Our range of products comprises amongst others effusion cells, electron beam evaporators, valved sources for phosphorus or arsenic, gas cracke cells for hydrogen or oxygen and a variety of sources for growth and doping applications used in semiconductor production, scientific research and nanotechnology.

\section{DRYOGENIC LIMITED \\ info@dryogenic.com \\ www.dryogenic.com}

Key Products: "Cryogen-Free" Cryogenic Systems

Dryogenic is an innovative new company with its own unique range of new, fully integrated, "cryogen-free" low temperature measurement systems. Because Dryogenic systems do not require any liquid Helium; they are easy to use, do not require specialized support infrastructure and have low cost of ownership. Dryogenic systems are cross-functional, as well being excellent instruments for measuring physical properties (magnetic, electrical and thermometric); their use can be easily expanded to meet the needs of the "experimentalist" by providing a modern, open platform for the user to incorporate their own measurement technologies.

\section{EASYLAB TECHNOLOGIES LTD. \\ info@easylab.co.uk}

www.easylab.co.uk

Key Products: Diamond Anvil Cells; Spectroscopy Systems; Pressure Cells easyLab is the de facto provider of instruments that enables science under pressure. easyLab designs, develops, manufactures, supplies and supports scientific equipment that extends the boundaries of experimental science into the extreme condition of high pressures. Our products include diamond anvil cells, piston-cylinder pressure cells, electric discharge micro-drillers, photoluminescence systems, Raman spectrometers for DACs and much more. Visit our website at www.easyLab.co.uk for more information.

\section{ECOPIA CORP. \\ sales@ecopia21.co.kr \\ www.ecopia21.co.kr}

Key Products: (Variable temperature) Hall Effect Measurement System; Probe Station; Heat Treatment System

Ecopia is a leading supplier of Hall Effect Measurement Systems which now include the HMS-5000 with variable temperature from $80 \mathrm{~K}$ to $330 \mathrm{~K}$. The magnet moves automatically via software control for greater convenience. Measure bulk/sheet carrier concentration, mobility, hall coefficient, resistivity, magneto-resistance, P/N Type. Check contacts with I-V \& I-R curve capability. Includes automatic magnet movement via software control. Economical HMS-3000 still available with new choices in Spring Clip sample mounting boards.
EDAX INC.

info.edax@ametek.com

www.edax.com

Key Products: Energy Dispersive X-ray; EBSD; X-ray Detectors

EDAX provides "Results with the Greatest Confidence." EDAX has led the industry as the technical innovator and the world's largest supplier of EDS, EBSD, WDS and Micro-XRF systems. Accurate analytical results require solid foundations and EDAX is the only company to achieve this through Expert ID and the Genesis Apex system. Orbis leads the way with a new standard in analytical flexibility for MicroXRF applications. EDAX products provide a powerful and unique combination of elemental and structural information to provide a complete solution for whatever your application.

\section{ELECTRON MICROSCOPY SCIENCES \\ sgkcck@aol.com \\ www.emsdiasum.com}

Key Products: Microscopy Supplies; Material Specimen Preparation Electron Microscopy Sciences (EMS) will have on display their comprehensive line of chemicals (material embedding kits), supplies and equipment (polishers, grinders, manipulators, disc punches, tripods, and lapping machines) for microscopy and all of the related material research fields. As well, Diatome will be exhibiting their Diamond Knives for materials microtomy, including the unique UltraSonic Oscillating Diamond knife for compression free sections.

\section{ELSEVIER}

\section{www.elsevier.com}

Key Products: Books; Journals; Electronic Products

Elsevier-the world-leading materials science publisher. Visit the Elsevier booth at the MRS Fall Meeting to pickup free sample copies of all our materials science research journals including the new journal for 2009 Nano Today, and to speak to an Elsevier representative. For the latest from Elsevier's materials science research publications, visit www.elsevier.com/materials.

\section{EUROPEAN SCIENCE FOUNDATION (ESF) www.esf.org}

The European Science Foundation (ESF) is an independent, non-governmental organization of national research organizations. ESF's membership currently includes 77 influential national funding agencies, research-performing agencies and academies from 30 nations. Since its establishment in 1974, ESF has assembled a host of research organizations that span all disciplines of science in Europe, to create a common platform for cross-border cooperation. Through its activities and instruments, ESF has made major contributions to science in a global context. The ESF covers the following scientific domains: Humanities; Life, Earth and Environmental Sciences; Medical Sciences; Physical and Engineering Sciences; Social Sciences; Marine Sciences; Nuclear Physics; Polar Sciences; Radio Astronomy Frequencies; and Space Sciences.

\section{EVANS ANALYTICAL GROUP \\ marketing@eaglabs.com} www.eaglabs.com

Key Products: Analytical Services

Evans Analytical Group ${ }^{\circledast}$ (EAG) is the world's leading, fully integrated and independent materials characterization lab network delivering world class testing services and expertise in surface analysis, trace elemental analysis, electron microscopy, failure analysis and circuit edit. EAG offers a comprehensive suite of over 30 analytical techniques and services supported by a fleet of 150 major instruments via 21 EAG locations across Asia, Europe and the U.S. Techniques/Services include: SIMS, TOF-SIMS, XPS, AES, FTIR, GDMS, IGA, ICP-OES/MS, LA-ICP-MS, LEXES, TEM/STEM, SEM, EDS, Dual Beam FIB/SEM, XRF, XRD, XRR, TXRF, AFM/SPM, RBS, HFS, NRA, PIXE, Raman, GC/MS, Chip Decapsulation/Deprocessing, Electrical Localization (Photon Emission, OBIRCH, TIVA, Liquid Crystal), RTX, SAM, FIB Circuit Edit, ESD and Latchup. 
FEI COMPANY

fei_info@feico.com

www.fei.com

Key Products: SEM; TEM; DualBeam SEM/FIB

FEl Company delivers the most innovative solutions for imaging, characterization and prototyping at the nanoscale. As the only company focused exclusively on the success of the worldwide microscopy community, FEl provides the most advanced TEM, SEM, and DualBeam ${ }^{\mathrm{TM}}$ solutions to specifically address the needs of materials science, life science, and electronics applications.

\section{FISCHIONE INSTRUMENTS \\ info@fischione.com}

www.fischione.com

Key Products: Electron Microscope Accessories; Plasma Cleaner; lon Mill

Fischione Instruments features a full line of Electron Microscopy Instrumentation. TEM Specimen Preparation Instruments include the Twin-Jet Electropolisher, Dimpling Grinder, Ultrasonic Disk Cutter, lon Mill, and the Plasma Cleaner which eliminates contamination in TEM and SEM applications. The NanoMill combines ultra-low ion energies and a concentrated beam for artifact-free preparation. The Automated Sample Prep (ASaP) System (Patent Pending) significantly enhances the image quality and analytical data derived from SEM specimens. Imaging Instruments include the high angle Annular Dark Field (ADF) detector for high resolution STEM imaging. The Model 2000 TEM Tomography Holder series includes specimen holders that allow high tilt and extended fields of view and are available in single-, dual- and on-axis versions.

\section{FLACKTEK, INC.}

\section{speedmixer@flacktek.net}

www.speedmixer.com

Key Products: Mixing Machines; Laboratory Mixers; High-speed Mixing Discover the unique possibility of Non-Invasive Mixing ${ }^{\mathrm{TM}}$ ! FlackTek, Inc. will be demonstrating the lab size SpeedMixer ${ }^{\mathrm{TM}}$ which has the capacity to mix samples from 3-700 grams, offers quick and uniform mixing and absolutely NO CLEAN-UP! Able to disperse, as well as mix, powders, putties, pastes, low viscosity materials, without air entrapment, and all done in a matter of seconds. Stop by our booth and ask how to make your mixing operations more efficient and precise.

\section{FUJIFILM DIMATIX, INC.}

info@dimatix.com

www.dimatix.com

Key Products: Materials Deposition Printer; Materials Deposition Cartridge Other Printheads and Systems

With the Dimatix Materials Printer (DMP), FUJIFILM Dimatix has advanced ink jetting to enable high-performance micro-precision deposition of a wide range of "inks" tailor fit to specific applications. It is the industry's first lowcost, cartridge-based piezo inkjet printing system that enables direct deposition of fluids for proprietary research allowing faster and less expensive product development. The MEMS-based inkjet head coupled to a disposable cartridge allows researchers to deposit the materials they have synthesized.

\section{GATAN, INC.}

\section{info@gatan.com}

www.gatan.com
MRS

CORPORATE

AFFILIATE
Key Products: Analytical TEM Instruments; Specimen Preparation; Digital Imaging

Gatan designs and manufactures instruments and products for electron microscopes that enable and advance EM applications. Gatan is the recognized leader in the industry and our products set the industry standards. Our engineers understand the application criteria of our customers and provide them with the right solutions. GATAN GETS IT!
GELEST INC.

info@gelest.com

www.gelest.com

Key Products: Organosilanes; Organometallics; Silicones

Gelest is a manufacturer of silanes, modified and reactive silicones as well as metal organics including germanium and tin compounds. Gelest also manufactures a broad range of metal alkoxides and metal diketonates. Gelest provides materials at both R\&D and commercial quantities. Products are used in microelectronic and optical coatings, sol-gel ceramics, composites and polymer synthesis.

\section{GEMS \& CRYSTALS UNLIMITED}

jeweler@mindspring.com

www.gemsandcrystalsunlimited.com

Key Products: Jewelry and Gemstones; Minerals and Crystals; Specialized Cutting for Science and Industry

Gems \& Crystals Unlimited specializes in custom cutting of research minerals for industry, NASA, Goddard, etc. We also offer outstanding gemstones, diamonds, rubies, sapphires, emeralds, tanzanites, etc. Customized gold and platinum jewelry. Complete custom work, including engagement, anniversary and any special celebrations for you! Huge array of antique jewelry in gold, platinum and silver, cameos, cufflinks, pins and collectibles. Also available are crystals and minerals of excellent quality and price.

\section{GOODFELLOW CORPORATION \\ info@goodfellow.com}

www.goodfellow.com

Key Products: Materials for Research \& Development

Goodfellow supplies small quantities of metals, alloys, ceramics and polymers for research, development and prototyping applications. Our web catalog lists a comprehensive range of materials in many forms including rods, wires, tubes and foils. There is no minimum order quantity and items are in stock ready for immediate shipment worldwide with no extra shipping charge. Custom-made items are available to special order.

\section{HALCYONICS}

info@halcyonics.de www.halcyonics.de

Key Products: Active Vibration Isolation Systems; Laboratory Tables

The anti-vibration specialists manufacture a great variety of active isolation solutions for any kind of vibration-sensitive measurement equipment. Besides standard products, Halcyonics has a strong focus on customer specific OEM solutions to meet the requirements for science and industry applications. Our systems are used in many fields of advanced micro- and nanotechnology, for instance, in biotechnology, material sciences, in the semiconductor field, LCD manufacture and many more. Halcyonics is presented through their own sales organizations in Germany and the USA; a global network of distributors offers support to customers worldwide.

\section{HAMAMATSU CORPORATION}

\section{usa@sales.hamamatsu.com}

www.sales.hamamatsu.com

Key Products: PMTs

Hamamatsu Corporation is the North American subsidiary of Hamamatsu Photonics K.K. (Japan), a leading manufacturer of devices for the generation and measurement of infrared, visible, and ultraviolet light. These devices include photodiodes, photomultiplier tubes, light sources, infrared detectors, photoconductive cells, and image sensors. The parent company is dedicated to the advancement of photonics through extensive research. This corporate philosophy results in state-of-the-art products which are used throughout the world in scientific, industrial, and commercial applications. 
HEATWAVE LABS INC.

techsales@cathode.com

www.cathode.com

Key Products: Substrate Heaters; Dispenser Cathodes; Vacuum Furnaces

HeatWave Labs is an engineering, design and manufacturing company that specializes in components and assemblies for the vacuum tube and vacuum equipment industries. Our expertise lies in the areas of thermionic cathodes and ion emitters and guns, ion sources and ionizers, ion pumps and controllers, vacuum tube design, processing and rebuilding, specialized high purity and refractory materials, UHV sample heating and filament products, temperature controllers and power supplies, ceramics and vacuum envelope assemblies and other related products.

\section{HERZAN LLC}

Exhibiting within the NanoLinks Group

sales@herzan.com

www.herzan.com

Key Products: Vibration Isolation; Acoustic Enclosures; Site Surveys

Herzan (www.herzan.com) is a comprehensive environmental solutions provider for the high precision research market. We specialize in high performance acoustic enclosures and cutting edge active vibration isolation technology. We also provide site survey services, EMI solutions, and passive vibration isolation options. Herzan is the leading solutions provider to AFM makers and end users. We also serve the SPM, STM, SEM, TEM, and optical microscopy communities. We offer off-the-shelf and custom solutions for OEMs and end users. No application is too sensitive or environment too noisy for our high performance solutions to overcome!

\section{HIELSCHER USA, INC.}

usa@hielscher.com

www.hielscher.com

Key Products: Ultrasonic Processor

Ultrasonic devices made by Hielscher are used worldwide for the deagglomeration and primary particle size reduction of powders in liquids. This includes the processing of catalysts, coatings, conductive pastes, cosmetics, ceramic composites, magnetic storage media, phosphors, inks and pigments, polishing media, and toners. In the production of micron-size and nano-size particles, ultrasound has proven to be more effective than many other technologies on lab, bench-top and production level. Equipment for feasibility studies and process optimization is available on good terms.

\section{HISCOCK \& BARCLAY, LLP}

www.hblaw.com

Hiscock \& Barclay, LLP, listed as a "Top 250 Firm" by The National Law Journal, is a full-service, 200-attorney law firm, with offices throughout the major cities of New York State, as well as in Boston, Washington, D.C. and Toronto, providing comprehensive legal and business counsel to a diverse client base in 28 practice areas. Established in 1855, the Firm's goal remains providing the highest quality legal services to clients through responsive, timely and cost-effective representation.

\section{HITACHI HIGH TECHNOLOGIES AMERICA, INC. emdwebsite@hitachi-hta.com}

www.hitachi-hta.com/emd

\section{Key Products: Scanning Electron Microscopes}

Hitachi High Technologies America, a global leader serving the needs for material science and nanotechnology development, provides a wide array of advanced electron microscopes. Our product line-up includes Scanning Electron Microscopes (SEM), Transmission Electron Microscopes (TEM), Variable Pressure SEM (VP SEM), Field Emission SEM (FE SEM), Focused lon Beam Systems (FIB) and the new TM-1000 Tabletop SEM (now available with EDS and 3-D View software). Our customers can expect more experience, reliability and customer support when choosing Hitachi electron microscopes.
HORIBA JOBIN YVON, INC.

info@jobinyvon.com

www.MolecularAndMicroanalysis.com

www.SpectroscopicEllipsometer.com

Key Products: Ellipsometer; Fluorescence Lifetime Spectrofluorometer; Raman Spectrometer; EDXRF Spectrometer; End Point Detector; CCD

World-Leading Manufacturer of High-Performance Spectroscopic Instrumentation for all Applications and Techniques from R\&D to Routine Analysis. Ellipsometers for measuring film thickness and optical constants, end point detectors for plasma analysis, trench depth monitoring, NEW low-cost and research grade Raman microscopes, EDXRF spectrometers, steady-state and lifetime spectrofluorometers with both TCSPC and phase capability, optical components, high performance CCDs and complete systems. Expertise in increasingly demanding, rapidly expanding applications requiring outstanding system performance including nanotechnology, semiconductors, pharmaceuticals, chemistry and biology and cutting-edge hybrid-technologies: AFM/Raman (nano-scale spatial resolution), Raman/PL, Raman/FT-IR, SEM/CL. Recent innovations include Multi-Frequency Fluorometry and incredibly FAST Raman scanning for high-speed hyperspectral chemical imaging. HJY's Applications Scientists are world-renowned experts and available for support. We have the answers for all your Molecular, Elemental and Micro-Analysis applications.

\section{HUNTINGTON MECHANICAL LABORATORIES, INC. vacman@huntvac.com}

www.huntvac.com

Key Products: Vacuum Chambers; Manipulators; Feedthroughs; Positioning Devices; Valves; Flanges/Fittings

The industry's largest selection of vacuum valves, flanges, fittings, and feedthroughs is available when you need it at Huntington. Also available are a wide assortment of roughing components including flexible hoses, traps, thermocouple and ionization gauge tubes. Standard, custom, or modified UHV positioning and motion devices can be provided to meet your special needs. Stainless steel custom chambers, tees, and crosses are supported by 35 years of experience in vacuum chamber design and fabrication. Our electrical feedthrough product line has been dramatically increased. We also now offer a Pulse Laser Deposition System! See all of our products on our website at www.huntvac.com.

\section{HVA, LLC}

sales@highvac.com

www.highvac.com

Key Products: Gate Valves; Rectangular Valves; Pendulum Valves

HVA is the premier manufacturer of high and ultrahigh vacuum valves for the semiconductor, scientific, and high-technology industries. Gate valves and rectangular valves are constructed out of 304 Stainless Steel, vacuum furnace brazed at $1100^{\circ} \mathrm{C}$ at $10^{-6}$ for maximum joint integrity. Product line includes stainless-steel gate valves, 3-position valves, angle valves, complete throttle/ isolation gate valve systems, stainless-steel/aluminum rectangular valves, pendulum valves, new rapid service slit valves for easy maintenance, and more.

HYSITRON, INC.

info@hysitron.com

www.hysitron.com

Key Products: TI 950 Nanolndenter; PI 95 TEM Picolndenter; TS 75 Nanolndenter

Hysitron is excited to launch the TI 950 Tribolndenter $^{\mathrm{TM}}$ nanomechanical test system featuring $25 \mathrm{x}$ faster feedback, a nanoNewton to Newton force range, faster sample throughput and an unprecedented $<30 \mathrm{nN}$ noise floor! Stop by our booth for the world's first view of the TI 950 and see how it redefines the world of nanomechanical testing. Hysitron will also be featuring the PI 95 Picolndenter ${ }^{\mathrm{TM}}$, the truly quantitative depth-sensing indenter capable of direct-observation testing in a TEM. 
IMAGE METROLOGY A/S

Exhibiting within the NanoLinks Group

sales@imagemet.com

www.imagemet.com

Key Products: Image Software

Celebrating their $10^{\text {th }}$ Anniversary in December 2008, Image Metrology provides the Scanning Probe Image Processor, SPIP, software package. SPIP is an image processing and data processing program with specialized utilities for microscopy, metrology, visualization and automation. The main purpose of the program is to provide tools that can correct for random and systematic errors and achieve the most correct measurements automatically.

\section{IMPERIAL-KING ABDULLAH UNIVERSITY OF SCIENCE \\ AND TECHNOLOGY (KAUST) PARTNERSHIP \\ kaust.materials@imperial.ac.uk \\ www.imperial.ac.uk/kaust}

Key Products: Saudi Arabia, KAUST, Imperial College

KAUST, opening in Saudi Arabia in September 2009, is an international, graduate level research university dedicated to inspiring a new age of scientific achievement in the Kingdom benefiting the region and the world. The Imperial-KAUST partnership, established March 2008, involves the Department of Materials and will enable one of the world's newest universities to build up its academic staff and curriculum in materials science and undertake collaborative research with their new members of staff.

\section{INEL, INC.}

inelinc@aol.com

www.inel.fr Key Products: X-ray Diffractometers; Position Sensitive Detectors; Power
Diffractometers

Serving the x-ray diffraction community for over 30 years, Inel is one of the world's leading suppliers of quality $x$-ray diffractometer systems incorporating curved or linear position sensitive detectors. Applications include powders, texture analysis, thin films, combinatorial, chemistry and materials analysis, reflectometry, microdiffraction, polymers, capillaries, in situ, on-line, transmission and reflection, small angle scattering, and variable temperature dynamic studies. We offer new systems and also hardware and software upgrades to existing instruments. Please inquire about our new Equinox diffractometer line.

\section{INFICON}

reachus@inficon.com

www.inficon.com

Key Products: Thin Film Deposition; Quartz Crystal Microbalance Research Vacuum Gauges and Components

INFICON thin film deposition controllers and monitors control deposition rate and thickness of the most complex processes with unsurpassed measurement speed and precision. INFICON quartz crystals offer the highest reliability for millions of successful process runs. Available in 5 or $6 \mathrm{MHz}$ with gold, silver or alloy electrodes, INFICON crystals are $100 \%$ factory tested to ensure quality. INFICON also provides residual gas analyzers, particle detectors, leak detectors, RF sensors, sensor integration and analysis software, vacuum gauges, valves, fittings and feedthroughs.

\section{INNOV-X SYSTEMS, INC.}

\section{info@innovxsys.com}

www.innov-xsys.com

Key Products: Portable XFR Technology

Innov-X Systems, founded in 2001, pioneered tube-based portable XRF for true field analysis. Simultaneously measure 25 elements, Mg - U, from PPM to $100 \%$ in seconds. No sample prep required. Thousands of Innov-X analyzers are used worldwide. Recently ranked $7^{\text {th }}$ Top Company in Manufacturing by Inc.com for Fastest Growing Private Companies in America, Innov- $X$ is headquartered north of Boston, with full service offices in Europe and throughout the Asia/Pacific. The X-50 Mobile won the 2007 IBO Industrial Design Gold Award.

\author{
INTERNATIONAL CENTRE FOR \\ DIFFRACTION DATA (ICDD) \\ info@icdd.com \\ www.icdd.com
}

Key Products: Powder Diffraction File (PDF-4+; PDF-2, PDF-4/Organics)

ICDD's material identification databases are designed for rapid materials identification and interfaced with diffractometers and data analysis systems of the world's leading software developers and manufacturers of X-ray equipment. The File is available in PDF-2 Release 2008 (211,107 entries), PDF-4+ 2008 (285,402 entries), PDF-4/Minerals 2008 (29,607 entries) and PDF-4/Organics 2009 (370,844 entries). ICDD promotes the application of materials characterization methods by sponsoring the Denver X-ray Conference; its proceedings, Advances in X-ray Analysis and the journal, Powder Diffraction.

\section{INTERNATIONAL UNION OF CRYSTALLOGRAPHY www.iucr.org}

Key Products: Journals; Reference Books; Online Services

The IUCr booth will showcase our journals covering research topics in materials science: Acta Crystallographica Section B Structural Science, Journal of Applied Crystallography and Journal of Synchrotron Radiation. Authors benefit from high impact factors, long citation half-lives, free colour and a number of innovative online services including a new interactive figure toolkit that allows the creation of enhanced structural illustrations. Drop by for a demonstration of International Tables Online, an essential resource for materials scientists.

\section{IOP PUBLISHING}

info@ioppubusa.com

journals.iop.org

Key Products: Leading Journals including Nanotechnology, JPCM, MSMSE and NJP

IOP Publishing is an international, not-for-profit, learned society publisher. Our catalogue comprises of many leading journals including Nanotechnology, Journal of Physics: Condensed Matter, Modelling and Simulation in Materials Science and Engineering and New Journal of Physics. We also publish many magazines including Physics World and Compound Semiconductor and community websites such as physicsworld.com, compoundsemiconductor.net and nanotechweb.org. Stop by our booth for a free sample copy of one of our printed publications, or for a personal demonstration of our award-winning electronic journals service and community websites. Visit IOP Publishing at journals.iop.org.

IXRF SYSTEMS, INC.

info@ixrfsystems.com

www.ixrfsystems.com

Key Products: Microanalysis Systems; XRF for SEM

IXRF offers five different SDD EDS detector configurations, $10 \mathrm{~mm}^{2}, 30 \mathrm{~mm}^{2}$, and $50 \mathrm{~mm}^{2}$, covering a wide gamut of applications, making IXRF the largest distributor of SDD's for the microanalysis industry. New X-ray Mapping features are now available to further enhance its vast line of SDD's showing improved speed and graphic capabilities. IXRF demonstrated more advancement in the world's only commercially available Micro-XRF tube adapted to the Scanning Electron Microscope. A new tube, "Super Flux," was introduced with a 10 micron excitation area along with an 8 position filter wheel to lower detection limits even more. By the addition of XRF to the microanalysis industry, customers can now take advantage of their existing EDS detector and use their SEM as a micro XRF analyzer. IXRF has fully integrated the XRF quantitative software into our EDS2008 software, allowing for trace analysis for all non-conductive samples as well as thickness coating measurements for the semiconductor industry. 
JANIS RESEARCH COMPANY, INC.

sales@janis.com

www.janis.com

Key Products: Continuous Flow and Reservoir Cryostats; $4 \mathrm{~K}$ and $10 \mathrm{~K}$ Mechanical Closed-Cycle Refrigerators; Micromanipulated Probe Stations

Please visit Janis Research in the NanoLinks aisle. Janis Research offers cryogenic systems for all research applications, including nano-scale science and technology. We offer systems that cover the entire low temperature range you need, in a variety of environments. They include magnetic fields, optical access, fiber optic cables, shielded high frequency coaxial cables and a variety of other customized options as dictated by your experimental requirements.
JEOL USA, INC.

salesinfo@jeol.com

www.jeolusa.com
KEITHLEY INSTRUMENTS, INC.

info@keithley.com

www.keithley.com

Key Products: Test and Measurement Equipment

Keithley Instruments, the leader in solutions for emerging measurement needs, continues its tradition of providing industry-leading sensitive and precision electrical measurement tools for a wide range of research applications in physics and materials, including nanotechnology, semiconductors, polymers, superconductivity, optoelectronics, organics, and biomaterials. New and featured products include Series 3400 pulse and pattern generators, additions to the Series 2600 System SourceMeter ${ }^{\circledast}$ line, and integrated instrumentation options for the Model 4200 Semiconductor Characterization System.

\section{KEMSTREAM \\ info@kemstream.com}

www.kemstream.com

Key Products: ALD Vaporizers; CVD Vaporizers; Sublimators; Liquid Panels

KEMSTREAM manufactures advanced vaporizers specially designed for CVD, ALD and all other gas phase processes. KEMSTREAM DLI (Direct Liquid Injection) vaporizers and sublimators are able to vaporize all solid and liquid precursors including low vapour pressure, thermally labile and viscous ones. They work from vacuum to atmospheric pressure and deliver accurate, repeatable and stable vapours flows. KEMSTREAM also provides stand alone injection heads/atomizers for spray pyrolysis/pyrosol processes and liquid panels for air sensitive liquid handling. developments enable customers to advance scientific research and manufac ing applications. Stop by for information on our full line of electron microscopes and novel mass spectrometers.

\section{k-SPACE ASSOCIATES, INC. requestinfo@k-space.com www.k-space.com}

Key Products: KSA 400 Rheed Analysis System; KSA MOS Multi-Beam Optical Sensor; KSA BandiT Temperature Monitor

Since 1992, k-Space Associates has been a leading supplier of advanced instrumentation and software for the surface science and thin-film technology industry. k-Space sets the standard for analytical RHEED with the kSA400. kSA MOS yields in situ curvature, stress, and strain while the new kSA MOS Ultra-Scan provides full two-dimensional stress mapping of samples up to $200 \mathrm{~mm}$. kSA RateRat monitors real-time deposition rate and optical constants. Our kSA BandiT, for monitoring semiconductor substrate wafer temperature during film growth, now works for GaN!

\section{KDF ELECTRONIC \& VACUUM SERVICES, INC \\ sales@kdf.com \\ www.kdf.com}

Key Products: Inline Sputter Systems; Cluster Sputter Systems; Etching Systems

KDF Electronic \& Vacuum Services, Inc. produces original and re-manufactured inline-sputtering tools for the mainstream silicon, emerging materials and flat-panel display markets. KDF produces an advanced cluster sputter and etch platform, the Ci. KDF systems are used in the production of semiconductors, photomasks, telecommunications networks, wireless circuits, gallium arsenide (GaAs), high-density interconnect, sensors, opto-electronics, flat panel display and radio frequency power devices. KDF is located in Rockleigh, New Jersey, USA, and has representatives in Europe, Japan, Taiwan, Singapore, Malaysia China, and Korea.

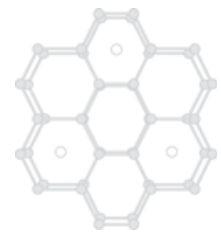

\section{KIMBALL PHYSICS, INC.}

info@kimphys.com

www.kimballphysics.com

Key Products: Electron Guns; Ion Guns; Electron Sources; Cathodes; Floating Power Supplies; UHV Vacuum Fittings and Chambers; Faraday Cups

Electron Guns and Ion Guns: Energies $5 \mathrm{eV}$ to $100 \mathrm{keV}$, electron sources, cathodes, Faraday cups. Options: Energy sweeping, rastering, pulsing, blanking, emission current feedback stabilization, computer control. UHV Components: Multi-CF Fittings, vacuum chambers, eV Parts. Applications: Surface physics, vacuum physics, charge neutralization, $x$-ray generation, cathodoluminescence, phosphor testing, semiconductor processing, RHEED, ESD, custom.

\section{KLA-TENCOR CORPORATION \\ info@kla-tencor.com}

www.kla-tencor.com

Key Products: Surface Metrology, P-16 Profiler; Alpha Step IQ, HRP 340

At KLA-Tencor's SMD product group, our market segments span semiconductor and data storage manufacturing, MEMS, optoelectronics, material science and general scientific research-a range of industries that measure surface topography to control their process. SMD's products range from benchtop stylus profilers used in research environments to automated high resolution profilers for advanced IC production fabs.

\section{KP TECHNOLOGY LTD.}

sales@kptechnology.Itd.uk

www.kelvinprobe.com

Key Products: Scanning Kelvin Probe; UHV Kelvin Probe

KP Technology will be demonstrating the unique height regulating "Baikie System" SKP5050 Scanning Kelvin Probe this year. This high resolution, noncontact and non-destructive device measures changes in work function and surface potential. Applications include semiconductors, organic layers, thin films, solar cells, corrosion and nanotechnology. Bring your own samples and let us show you how this SKP or our other ambient and UHV Kelvin Probes can work for you. Visit www.kelvinprobe.com for more information. 
KSV INSTRUMENTS, INC.

info@ksvinc.com

www.ksvltd.com

Key Products: Langmuir Blodgett Instruments; Interfacial Sheer Rheometer; Contact Angle Meters

KSV Instruments manufactures instruments for research and analysis of Contact Angle and Surface Tension as well as Langmuir Blodgett Instruments, a Quartz Crystal Microbalance, SPR, a PM-IRRAS, Interfacial Shear Rheometer and other LB characterization instruments. Surface Science and Nanotechnology application can benefit from the KSV extensive application experience and innovative instruments.

\section{KURT J. LESKER COMPANY}

salesus@lesker.com

international@lesker.com

www.lesker.com

Key Products: Pure Targets and Materials; Vacuum Components Deposition Systems; Atomic Layer Deposition

Stop by our booth to discuss your materials research challenges. We offer sputtering targets, evaporation sources, deposition systems, components and services for a wide variety of materials research related processes including: magnetron sputtering; e-beam evaporation; organic materials evaporation and Atomic Layer Deposition (ALD). The Kurt J. Lesker Company is one of the world's leading suppliers of R\&D and production materials.

\section{LAKE SHORE CRYOTRONICS, INC.}

sales@lakeshore.com

www.lakeshore.com

Key Products: Hall Effect Measurement Systems; Probe Stations; Cryogenic Instruments and Sensors

Lake Shore manufactures cryogenic, closed cycle refrigerator-based, electromagnet and superconducting magnet-based, high vacuum, and load lock probe stations, as well as Hall effect measurement systems (HMS). The probe stations can be used for DC, RF, microwave (up to $67 \mathrm{GHz}$ ), and magnetotransport measurements on devices and wafers. Features include temperatures from $1.5 \mathrm{~K}$ to $475 \mathrm{~K}$, horizontal or vertical magnet fields, up to 6 manipulated probe arms, vacuum to $10^{-7}$ torr, and up to 4 -inch wafer probe capabilities. The HMS feature fields to $9 \mathrm{~T}$, temperatures from $2 \mathrm{~K}$ to $800 \mathrm{~K}$, up to 6-inch wafers or accommodation of 4 samples. Measurements including resistance, I-V curves, Hall coefficient, mobility, and carrier concentration can be made on compound semiconductors, semi-insulators, and heterostructures. Quantitative Mobility Spectrum Analysis (QMSA ${ }^{\oplus}$ ) software resolves individual carrier mobilities and densities in multi-carrier devices such as quantum wells and HEMTs.

\section{LAYTEC GMBH}

\section{info@laytec.de}

www.laytec.de

Key Products: Optical In situ Sensors for Epitaxy; OLED and Sputter Processes LayTec is a major provider of in-situ monitoring sensors for process monitoring and control in thin-film processes. Recently, the application range of LayTec's systems has been expanded to amorphous and organic thin-film growth processes (sputter deposition, VTE, OVPD). Its products measure parameters as substrate temperature, growth rate, layer thickness, doping levels, ternary material composition, surface roughness and strain-induced substrate bowing, all of them with extreme precision already during the deposition process.
LEICA MICROSYSTEMS INC.
info@leica-microsystems.com
www.leica-microsystems.com

Key Products: EM UC6 Ultramicrotome; M205 C Stereomicroscope; DMI3000 M Inverted Microscope

Your Image Starts Here! Rely on Leica Microsystems for high-quality sample preparation for TEM, SEM, AFM, and LM. Designed for comfort and convenience, the Leica EM UC6 Ultramicrotome puts total comfort and convenience at your fingertips. Leica Microsystems will also show the Leica M205 C zoom stereomicroscope with unique Fusion Optics for high resolution imaging throughout the entire 20:1 zoom range, inverted microscopes uniquely designed for materials research, and more.

\section{MAD CITY LABS, INC.}

sales@madcitylabs.com

www.madcitylabs.com

Key Products: Nanopositioners; Piezo Scanners; Precision Motion Control Mad City Labs designs and manufactures high precision, piezo based nanopositioning devices for research and industry. Our products incorporate innovative, flexure guided designs, proprietary PicoQ sensors and closed loop control resulting in extremely low noise and superior stability. System attributes include picometer resolution, high speeds, real time position sensing and are suitable for metrology, microscopy, lithography, materials testing and more. We offer innovative products, competitive pricing and superior customer support. New Products include Nano-HS series for ultra high resolution and speed applications, Nano-SP for Micro/Nano applications.

\section{MANEY PUBLISHING \\ maney@maney.co.uk \\ www.maney.co.uk}

Key Products: Journals; Books; Online Collections

Maney Publishing, founded in 1900, became the official publisher to the Institute of Materials, Minerals and Mining in 2001 and has since established an expanding materials science and engineering portfolio comprising twenty leading international journals and over 200 books. Visit www.maney.co.uk/ materials to view the full collection.

\section{MANTIS DEPOSITION LTD.}

sales@mantisdeposition.com

www.mantisdeposition.com

Key Products: Deposition Systems; Nanoparticle Systems; Deposition Sources MANTIS Deposition is dedicated to the manufacture of high-quality deposition components and systems for cutting-edge applications such as nanotechnology, MBE, PVD and ion-beam assisted deposition. Our product offerings include: nanoparticle deposition sources and systems, RF atom and RF ion sources, mini e-beam evaporators, sputter cathodes and thermal gas crackers as well as modular R\&D deposition systems.

\section{MBRAUN, INC.}

info@mbraunusa.com

www.mbraunusa.com

Key Products: Gloveboxes; Evaporators; Solvent Purification Systems

MBraun offers a full line of newly redesigned gloveboxes, solvent purifiers and gas purification systems. MBraun is capable of designing and manufacturing high quality systems engineered to your specific requirements. Additional features include gloveboxes with integrated evaporators, high temperature vacuum ovens, integrated spin coaters, solvent vapor removal systems, low temperature storage, $\mathrm{O}_{2} / \mathrm{H}_{2} \mathrm{O}$ analyzers and more. With over 30 years of glovebox engineering experience, MBraun is able to supply complete turnkey solutions for all your controlled environment needs. Please stop by our booth or visit us at www.mbraunusa.com for more information. 
MCALLISTER TECHNICAL SERVICES

solutions@mcallister.com

www.mcallister.com

Key Products: Atomic Layer Deposition System; UHV Kelvin Probes; Custom XYZ Manipulators

McAllister Technical Services will exhibit the UHV Kelvin Probe for contact potential measurements. Also on display will be their full range of custom UHV devices such as bellows-sealed positioners, XYZ manipulators, quickentry load-lock system, magnetic linear motion feedthrough and differentiallypumped rotary motion platforms.

\section{VACUUM PRODUCTS, LLC}

sales@mdcvacuum.com

www.mdcvacuum.com

Key Products: Flanges and Fittings; Valves; Viewports and Glass Components; Feedthroughs; Motion and Manipulation Instruments; Thin Film Deposition; Custom Engineering

MDC Vacuum Products, LLC stocks thousands of off-the-shelf vacuum components. The MDC product line consists of flanges, fittings, valves, roughing hardware, vacuum measurement and motion and manipulation instruments, thin film equipment and surface science chambers. MDC's electrical and optical division, Insulator Seal, features the industry's most comprehensive line of hermetically sealed electrical feedthroughs and optical components for even the most demanding Ceramic-to-Metal seal applications. MDC's SemiSystems division specializes in the manufacture of ultra-high purity gas and fluid delivery systems. Capabilities include welding of gas lines, vacuum weldments, tube bending and assembly. Visit our technically based Web sites: www.mdcvacuum.com, www.insulatorseal.com, and www. mdcsemisystems.com.

\section{MEMS AND NANOTECHNOLOGY EXCHANGE www.mems-exchange.org}

Key Products: Prototyping Service; Low-volume Manufacturing; Design \& Engineering

The MEMS and Nanotechnology Exchange (MNX) is the country's leading prototyping service for Micro- and Nano-technology devices. The MNX was established by DARPA in 1998. We provide assistance to researchers and developers across all arrays of application domains including: medical; aerospace; automotive; industrial; military; consumer products; etc. Our specialty is making available to our customers the broadest and most diverse array of fabrication technologies in a convenient, efficient, and cost-effective manner.

\section{MERCURY COMPUTER SYSTEMS \\ 3d_info@mc.com \\ http://3dviz.mc.com}

Key Products: 3D Visualization Software

Mercury Computer Systems, Visualization Sciences Group, is the leading provider of 3D visualization software for materials science, geosciences, oil and gas, manufacturing, and engineering. Our solutions range from 3D components for application developers to advanced 3D visualization software, from desktop to clusters and immersive VR, bringing high-performance visualization and dynamic GPU computation to our customers' demanding projects. Mercury Computer Systems has worldwide R\&D, support and sales locations.
METROHM USA, INC.

info@metrohmusa.com

www.metrohmusa.com

Key Products: Electro Chemical Systems; Impedance Systems; Sensors; QCM Hear more about how the best of Brinkmann is now Metrohm USA! Featuring Eco Chemie Autolab electrochemistry systems for material research: Modular PGSTAT 302N potentiostats and galvanostats for electrochemical analysis and impedance characterization of sensor and material components offer low-current and high-speed scanning options as well as integration with QCM, SPR and other measuring systems. Metrohm Computrace analysis systems are used for electrochemical determination of trace levels of material and sensor components.

\section{MICRO MATERIALS LIMITED}

info@micromaterials.co.uk

www.micromaterials.co.uk

Key Products: NanoTest System; MicroTest System

Micro Materials Ltd. have been world leaders in the field of nanomechanical property measurements since 1988 . Today the powerful NanoTest ${ }^{\mathrm{TM}}$ system is much more than just a nanoindentation instrument. The excellent range of testing modules available provide a comprehensive tool kit for mechanical property investigation and, together with unrivalled stability and accuracy, this makes the NanoTest ${ }^{\mathrm{TM}}$ the most flexible and accurate instrument of its type. The NanoTest ${ }^{\mathrm{TM}}$ is a truly modular system, offering unique modules such as high temperature nanoindentation to $750^{\circ} \mathrm{C}$, indentation in liquids and nano-impact testing. Visit the MML booth to learn more about what the NanoTest ${ }^{\mathrm{TM}}$ can do for you!

\section{MICRO PHOTONICS INC}

infoca@microphotonics.com

www.microphotonics.com

Key Products: Nano/Micro Mechanical Testing Instruments; NonDestructive Testing; Thin-Film Analysis

Micro Photonics is a leading source of advanced scientific research instrumentation for mechanical, surface analysis, bio, and in-vivo applications. Our extensive product line includes our own Nanovea brand mechanical instrumentedindentation scratch and adhesion, tribology and profilometry and topography instruments. We offer extensive selections of X-ray microtomography equipment for non-destructive internal imaging, instruments for materials and thin film thickness, diffractometers, versatile AFM, NSOM and SPM solutions.

\section{MICROFAB TECHNOLOGIES, INC.}

microinfo3@microfab.com

www.microfab.com

Key Products: Precision Microdispersing Systems; Inkjet Printing Systems; Jeblab-4; Jeblab-II

MicroFab is introducing new microdispensing products in Fall 2008 for a range of applications including precision microsphere generation. For the last ten years, we have been offering Jetlab ${ }^{\oplus}$ printing machines that provide researchers in microelectronics, photonics, bio-medical, defense and security an important too to develop functional materials, processes and prototypes. Companies are using our equipment in manufacturing. Contact Dr. David Wallace at david.wallace@ microfab.com or visit our web site at www.microfab.com. 


\section{MIKROMASCH}

usa@mikromasch.com

www.spmtips.com

Key Products: AFM Probes; Calibration Standards; High Resolution Probes At MikroMasch, we strive to provide complete micromachining solutions for your research. MikroMasch offers one-stop shopping for all SPM accessories and MEMS customization service upon request. Our continuous efforts in improving and developing our probes resulted in a new probe, called Hi'RES, with its tip curvature radius of $1 \mathrm{~nm}$. This new product will contribute to your fine research leading to an even more advanced level. Please visit our web site at www.spmtips.com to review our product lines.

\section{MMR TECHNOLOGIES, INC.}

sales@mmr.com

www.mmr.com

Key Products: Hall Effect Measurement Systems; Seebeck Effect Measurement Systems; Variable Temperature Microprobes

MMR Technologies manufactures temperature controlled systems-cryogenic cooling systems and wide temperature range thermal stages - which find application in materials research in chemistry, biology, electrical engineering, and physics. These systems operate over the temperature range of $10 \mathrm{~K}$ to $730 \mathrm{~K}$ They are used for electrical resistivity, Hall effect, Seebeck effect, DLTS, MEMS, magnetoresistivity, and luminescence studies. They are also used in medical applications and the cooling and characterization of computer chips, electronic devices, laser diodes and thermal imaging devices as a function of temperature.

\section{MTI CORPORATION}

info@mtixtl.com

www.mtixtl.com

Key Products: Single Crystal Substrates; Tube and Box Furnaces; Polisher and Diamond Saw

MTI has been providing a total solution for materials research since 1995 . We supply crystal substrates and nanopowders from A to Z, desktop laboratory equipment, including cutting, polishing and high temperature box/tube furnaces, as well as compact XRD/X-Ray orientation.

\section{LABORATORIES, INC.}

\section{info@mvlaboratories.com}

www.mvlaboratories.com

Key Products: Ultra High-purity Inorganic Chemicals; Chlorides; Fluorides; Oxides; Custom Synthesis

MV Laboratories, Inc., founded in 1985, is a world leader in the manufacture of ultra high-purity inorganic chemicals for chemical analytics and synthesis, crystal growth, nano-materials production, specialty ceramics, optoelectronics, and research and development in a wide range of other industries. The company manufactures and stocks more than four hundred, $99.999 \%$ pure chemicals, including oxides, chlorides, fluorides, bromides, carbonates, and nitrates of seventy elements.

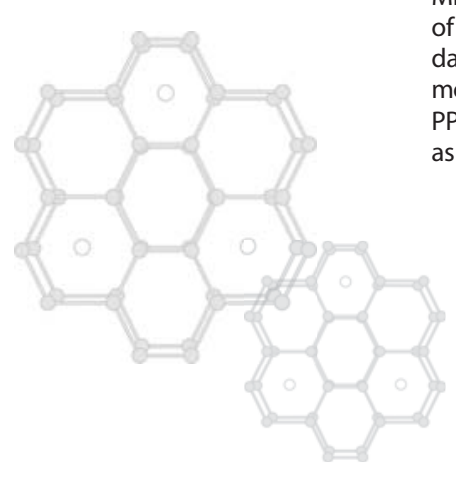

NANOANDMORE USA INC.

Exhibiting within the NanoLinks Group

usa@nanoandmore.com

www.nanoandmore.com

Key Products: AFM Probes; Nanoparticle Size Analyzer; Digital Holographic Microscope

NanoAndMore USA, Inc. is a nanotechnology distributor with products that include SPM probes and calibration standards from NanoWorld ${ }^{\mathrm{TM}}$, NANOSENSORS ${ }^{\mathrm{M}}$ and Budget Sensors ${ }^{\mathrm{TM}}$, Image Metrology SPIP software, Minus K vibration isolation products and scientific instruments. The Digital Holographic Microscope from Lyncée tec captures 3D images in real time and does not require vibration isolation. The Reflection model competes with white light and laser interferometry while the Transmission model competes with Confocal systems. The NanoSight nano-particle size analyzer gives a full distribution of all particles suspended in solution by particle count and percentage. We have most AFM probes in stock and can ship overnight. Contact: 877-521-1108 (toll free) or usa@nanoandmore.com.

\section{NANOFACTORY INSTRUMENTS AB \\ info@nanofactory.com}

www.nanofactory.com

Key Products: In situ TEM/SPM; AFM-TEM Systems; TEM Nanoindentation

Nanofactory Instruments is the world leader in providing specialized SPM systems (STM, AFM, Nanolndenter) designed to work in Transmission Electron Microscopes (TEM). These unique SPM-TEM instruments provide unprecedented opportunity to combine 3-dimensional nanomanipulation, STM-AFM imaging and in situ electrical and mechanical measurements with high resolution TEM imaging.

\section{NANOINK, INC.}

info@nanoink.net

www.nanoink.net

Key Products: NSCRIPTOR ${ }^{\mathrm{TM}}$ DPN $^{\circledR}$ System; 2D nano PrintArray ${ }^{\mathrm{TM}}$; Active Pen $^{\text {TM }}$ Arrays

Nanolnk is an emerging growth technology company specializing in nanometer-scale manufacturing and application development for the life science and materials industries. With Dip Pen Nanolithography ${ }^{\circledR}$ (DPN ${ }^{\circledR}$ ) technology and tools, Nanolnk is able to offer customers innovative solutions for precision nanoscale deposition using a variety of materials to create nanoscale features on diverse surfaces. The NSCRIPTOR ${ }^{\mathrm{TM}}$ is a complete turnkey DPN system with optimized hardware, software, and enabling consumables.

\section{NANOMAGNETICS INSTRUMENTS LTD. \\ info@nanomagnetics-inst.com}

www.nanomagnetics-inst.com

Key Products: Atomic Force Microscope; MK-Scanning Prope Microscope; SPM Control Electronics and Software

NanoMagnetics Instruments Ltd. is the leading expert in Scanning Hall Microscopy. SHPM can give a resolution up to $50 \mathrm{~nm}$ and a magnetic resolution of $6 \mathrm{nT} / \sqrt{ } \mathrm{Hz}$ at $4 \mathrm{~K}$, which provides fast, quantitative and totally non-invasive data. Our mK-SPM is operational at mK-300K range and is compatible with most crysostat systems. PPMS ${ }^{\circledR}$-SPM is designed to operate with QuantumDesign PPMS. And RT-SHPM is designed for ambient conditions. All can also operate as AFM, MFM or STM and can give realtime SHPM scans. 
NANOMECH, LLC

www.nanomech.biz

Key Products: Nanoparticle Deposition System-NanoSpray ; Advanced Lubricant Additive-NanoGlide ${ }^{\circledR}$

NanoMech is a nanoparticle-integrated product innovation company with a portfolio of award-winning platform technologies addressing six sectors:

1. Machining and manufacturing (spinoff: Duralor, product line: TuffTek ${ }^{\circledast}$ )

2. Nano-engineered lubricants (product line: NanoGlide ${ }^{\circledR}$ )

3. Biomedical coatings (product line: Multi-Care ${ }^{\mathrm{TM}}$ )

4. Nano-engineered packaging materials for extending the life of fresh foods (spinoff: GuardIN Fresh, product line: FreshFit ${ }^{\mathrm{TM}}$ )

5. The defense sector, particularly advanced body armor (product line: OmniArmor ${ }^{\mathrm{TM}}$ )

6. Nanoparticle deposition systems (product line: NanoSpray ${ }^{\circledast}$ )

\section{NANONICS IMAGING LTD.}

info@nanonics.co.il

www.nanonics.co.il

Key Products: Multiprobe SPM/NSOM/Confocal; AFM/Raman; TERS; AFM/SEM/FIB; Cryogenic NSOM/AFM/Confocal Raman

Single and Multiprobe AFM/NSOM/SPM Systems hallmarked by transparent optical and electron/ion beam integration. Ideal for multiprobe plasmonics, electrical characterization, photonics, thermal diffusivity, chemical writing, etc. On-line Raman/TERS, confocal, SEMs, FIBs, $10^{\circ} \mathrm{K}$ operation. Capable of all modes of AFM/NSOM with silicon or transparent AFM probes. Deep trench and side wall imaging capabilities, glass insulated electrical probes,

Nanoheater ${ }^{\mathrm{TM}}$ thermal conductivity, AFM-controlled gas/liquid nanochemical deposition, electrochemical probes, etc. Visit and see the first multiprobe SPM system! Up to 4 probes.

\section{NANONIS, INC.}

info@nanonis.com

www.nanonis.com

Key Products: Scanning Probe Microscopes; Oscillation Controller (PLL); Atomic Force Microscopes

Nanonis is specialized in the field of Scanning Probe Microscopy (SPM). We offer SPM control systems with highly reliable and custom-made software and hardware as well as outstanding services. Applying our immense SPM expertise, Nanonis scientists built a user-friendly and powerful SPM controller allowing engineers and scientists to fully focus on their core investigations.

Visit us at our booth where we will show you a live demonstration on a simulated Si-(111) surface and much more!

\section{NANOSENSORS}

Exhibiting within the NanoLinks Group

info@nanosensors.com

www.nanosensors.com

Key Products: AFM Probes; AFM Tips; AFM Cantilever

NANOSENSORS ${ }^{\mathrm{TM}}$ is specialized in manufacturing cutting edge scanning probes for Atomic Force Microscopy (AFM) preferred by scientists at universities, research institutes and industrial $R \& D$ centers. The product range comprises high quality standard probes, the AdvancedTEC probe, SuperSharp probes, High Aspect Ratio probes, Diamond Coated probes and many others, including customized solutions. In December, NANOSENSORS ${ }^{\mathrm{TM}}$ will introduce its new single and double wall Carbon Nanotube probes for high resolution imaging NANOSENSORS ${ }^{\mathrm{TM}}$ is a trademark of NanoWorld AG.

\section{NANOSURF AG}

info@nanosurf.com

www.nanosurf.com

Key Products: Atomic Force Microscopes; Scanning Tunneling Microscopes; AFM/STM Supplies

With excellent know-how in the fast growing field of nanoscience, Nanosurf's main focus is on the research and development of scanning probe microscopes (AFMs and STMs). Our innovative SPMs feature unparalleled ease of use, unmatched portability, and Swiss-quality craftsmanship, all at an affordable price. Stop by our booth to learn more about our popular easyScan SPMs, our Mobile S-the world's first battery-powered AFM, and our new Nanite AFM featuring batch programmable multiple measurement capabilities.

\section{NANOTOOLS GMBH}

Exhibiting within the NanoLinks Group

contact@nano-tools.com

www.nano-tools.com

Key Products: Scanning Probes for AFM and Scanning Near Field Microscopy nanotools $\mathrm{GmbH}$ is a fast growing company which designs, manufactures and markets tools for nanotechnology applications, including high quality scanning probes for atomic force and scanning near field microscopy. Nanotools' scanning probes are used in basic research and industrial R\&D as well as in production, quality control and yield management. The analyses performed cover the fields of microsystems, semiconductors, chemistry, materials science, biology, medicine and nanotechnology in general.

\section{NATIONAL NUCLEAR LABORATORY customers@nnl.co.uk}

www.nnl.co.uk

Key Products: Nuclear Reactor \& Fuel Cycle Technology; Waste \& Residue Management; Homeland Security \& Non-Proliferation

The UK's National Nuclear Laboratory (NNL) is a nuclear technology products and services provider. The business specializes in providing customers with tailored solutions by applying the right level of technical innovation and intellectual support. Our range of products and services include: Nuclear Reactor and Fuel Cycle Technology Services; Materials, Corrosion and Nuclear Chemistry; Waste and Residue Management; Plant Process Support; Environmental Management; Homeland Security and Non-Proliferation; and Specialist Analytical Services.

\section{NATIONAL RECONNAISSANCE OFFICE \\ dii@nro.mil}

dii.westfields.net

Key Products: DII Research \& Development Funding

R\&D Funding - The National Reconnaissance Office's Director's Innovation Initiative invests in advanced technologies, fosters innovation, and provides seed funding to push the boundaries of technology to dramatically improve our overhead reconnaissance capabilities. It presents an opportunity for developers not traditionally associated with the NRO to participate in building the National Reconnaissance Office of the 21 st Century.

\section{NATURE PUBLISHING GROUP}

nature@nature.com

www.nature.com

\section{Key Products: Journals}

Nature Publishing Group (NPG) offers a range of journals in the physical sciences portfolio-from the broad scope and excellence of Nature to specific titles in materials, physics, nanotechnology and photonics. Each journal carries a mix of research papers, review titles, news and views, and commentaries that will keep you abreast with the latest research in your area. Visit the NPG booth for your free sample copy, to find out about the latest Impact Factors or to subscribe to any NPG journal at a discounted conference rate. 
NEOCERA, LLC

sales@neocera.com

www.neocera.com

Key Products: Pulsed Laser Deposition; Pulsed Electron Deposition; Laser MBE with RHEED

Neocera creates, develops and promotes advanced thin film materials and deposition techniques. Founded in 1989 to commercialize technical expertise in cutting edge materials, Neocera is a world leader in the manufacture of Pulsed Laser Deposition (PLD) and Pulsed Electron Deposition (PED) systems for research and production applications. Neocera's nanotechnology products include Laser MBE systems with RHEED, Combinatorial PLD/PED Systems, and lon assisted-PLD Systems. Neocera offers complex oxide thin films on a foundry basis.

\section{NETZSCH INSTRUMENTS INC \\ NIB-Sales@netzsch.com}

www.e-thermal.com

Key Products: Thermal Analysis Instruments; Contract Testing

Thermal analysis, thermal properties measurement, thermal conductivity, in situ dielectric analysis, and contract testing services; featuring a new STA (simultaneous TGA-DSC/DTA) w. 25 nanogram resolution and $5 \mathrm{~g}$ sample load, DSC, TGA, DTA, coupling to MS \& FTIR for evolved gas analysis, Dilatometers for CTE and sintering optimization, Laser Flash Thermal Diffusivity/ Conductivity, TMA, DMA, DEA-Micromet-series cure monitoring by dielectric analysis in-process and lab-scale, Guarded Hot Plate and Heat Flow Meters for thermal conductivity acc. to ASTM standard methods.

\section{NIST}

www.nist.gov/srm

Key Products: Standard Reference Materials; Data and Calibration Services

NIST Standard Reference Materials supports accurate/compatible measurements by certifying and providing over 1100 SRMs with well-characterized composition or properties, or both. SRMs are used to perform instrument calibrations as part of quality assurance, accuracy of specific measurements and support new measurement methods. Standard Reference Data provides welldocumented numeric data to scientists and engineers for use in technical problem-solving, research, and development. The Calibration Services are designed to help in achieving high levels of measurements.

\section{NOR-CAL PRODUCTS, INC \\ ncsales@n-c.com}

www.n-c.com

Key Products: Custom and Standard Vacuum Components; Vacuum Chambers; Valves

Since 1962, Nor-Cal Products, Inc. has manufactured high and ultra-high vacuum components for many applications. Nor-Cal has earned a reputation worldwide for quality components, competitive prices and excellent customer service and is now ISO 9000-2001 registered. Standard products include: flanges; fittings, viewports, feedthroughs and flexible hoses; crystal monitors, manual and pneumatic valves; pressure control valves and controllers; heater jackets; foreline traps; and manipulators. Custom chambers, manifolds, feedthrough collars and baseplates can be manufactured from customer specifications, sketches or drawings. Entire systems can be supplied. Our extensive 3D Model Library is available on-line. Visit our website at www. n-c.com for more information.
nPOINT, INC.

Exhibiting within the NanoLinks Group

info@npoint.com

www.npoint.com

Key Products: Nanopositioning Systems; AFM Scanners

nPoint, Inc. manufactures ultra-precision motion and control devices for nano-scale research and manufacturing. Our products include a series of nanopositioning systems that consist of stages and control electronics. The positioning products enable rapid, precise, and repeatable motion and are used in applications ranging from life science to semiconductor industry.

\section{NT-MDT CO.}

spm@ntmdt.ru

Key Products: Scanning Probe Microscopes; Probe Nanolaboratories;

Cantilevers, Calibrations, Gratings, Test Samples for SPM

NT-MDT has been creating the equipment for nanotechnology research for more than 15 years, steadily holding the advanced positions regarding the quality standards, hi-tech developments, original technical solutions. Our mission is to be the premier provider of hi-tech products and service in the scanning probe microscopy age. Today NT-MDT produces different equipment lines: Scanning Probe Nanolaboratories, Scanning Probe Microscopes, SPM accessories and the modular nano-factories, but the range of products constantly expands.

\section{OCEAN OPTICS INC.}

info@oceanoptics.com

www.oceanoptics.com

Key Products: Spectrometers; Fiber Optic Accessories; Light Sources Ocean Optics is the creator of the world's first miniature fiber optic spectrometer and a leading supplier of optical-sensing systems for materials analysis and characterization of metals, ceramics, semiconductors and polymers. Among our latest innovations is a Laser-induced Breakdown Spectrometer, a broadband (200-980 nm) system for instant elemental analysis of trace elements in solids, solutions and gases. We also offer a line of high-precision metrology tools for thin film measurement, plasma analysis and optics characterization.

\section{OLYMPUS INDUSTRIAL AMERICA INC.}

sales@olympusindustrial.com

www.olympusmicroimaging.com

Key Products: Inverted Metallographs; Upright Microscopes; Stereo Microscopes

Olympus Industrial America's Micro-Imaging division, based in Orangeburg, New York, is responsible for sales and service of the complete range of Olympus microscopy products for use in industrial applications from production and inspection to research and quality control. Complimenting our line of materials analysis microscopes will be a range of digital cameras and Discover Series modular software packages. You will be impressed with the speed and accuracy of our software and cameras when archiving images, taking measurements/particle sizing or generating reports. Feel free to bring a sample to our booth to see the quality of Olympus Micro-Imaging products.

\section{OMICRON NANOTECHNOLOGY USA}

info@omicronus.com

www.omicron-instruments.com

Key Products: UHV SPM; Surface Science Instrumentation; MBE

Omicron NanoTechnology is the premier supplier of UHV instruments for nanoscience and research. We invite you to visit our booth to see the latest results from the next generation Low Temperature (down to 5K) Atomic Force Microscope with enhanced LHe hold time. The Variable Temperature AFM/STM is now available with a non-optical QPlus force sensor. We will also be highlighting the ESCA+, NanoESCA, Nanoprobe, and NanoSAM surface science systems. From thin film development to characterization, Omicron can help. 
ORIGINLAB CORPORATION

sales@originlab.com

www.originlab.com

Key Products: Origin 8 and OriginPro 8 Software

OriginLab publishes data analysis and graphing software. Our products provide comprehensive solutions for scientists and engineers who need to analyze, graph, and professionally present data. We have two offices in the United States: Northampton and Wellesley Hills, Massachusetts. Our main product, Origin, has been growing in popularity since 1991. Today, with over 100,000 licenses worldwide, Origin is used in over a hundred "Fortune 500 Global" companies and around a thousand colleges and universities.

\section{OXFORD APPLIED RESEARCH}

sales@oaresearch.co.uk

www.oaresearch.co.uk

Key Products: Nanocluster Systems; RF Sources; Mini E-Beam Evaporators Manufacturer of growth and processing equipment for semiconductor or thin film research. Core instruments include RF atom sources for high-quality oxide/nitride growth, e-beam evaporators, atomic hydrogen sources, nanocluster deposition sources for size-selected nanoparticle deposition, broadbeam RF and DC ion sources for sputter deposition or ion beam assisted deposition (IBAD), and a family of ion and electron guns for thin film analysis. Come and see us for more information on our new valved organic source.

\section{OXFORD INSTRUMENTS \\ info@ma.oxinst.com}

www.oxford-instruments.com

Key Products: Optical Spectroscopy; Materials Characterization; EBSD Oxford Instruments, with over 40 years of experience, is the world's leader in research and analytical instrumentation. Visit our booth to see the latest in superconducting magnet, cryogenic/variable temperature control technologies and cryogenic high vacuum pumps. We offer a range of analytical accessories for electron microscopy, including a range of EDX, WDX and EBSD detectors and analyzers. Oxford Instruments Pro-Serve has a global distribution and support organization with an emphasis on exceptional customer support.

\section{OXFORD UNIVERSITY PRESS \\ custserv.us@oup.com \\ www.oup.com/us}

Key Products: Aranson, Tsimring: Granular Patterns; Carlile, Willis: Experimental Neutron Scattering; Agranovich: Excitations in Organic Solids

Oxford University Press is a leading publisher of materials research titles. Visit us in Boston to see our newest books including: Aranson's Granular Patterns, Carlisle's Experimental Neutron Scattering, Agranovich's Excitations in Organic Solids, Banhart's Advanced Tomographic Methods in Materials Research and Engineering, Kisi's Applications of Neutron Powder Diffraction, Ghoniem's Instabilities and Self Organization in Materials, 2 Volume Set and Pozrikidis's Numerical Computation in Science and Engineering. Receive a $20 \%$ discount on all show purchases.

\section{PACIFIC NANOTECHNOLOGY, INC. \\ sales@pacificnano.com \\ www.pacificnano.com}

Key Products: Atomic Force Microscopes

Pacific Nanotechnology, Inc. provides products and services which facilitate advancements in Nanotechnology and Nanoscience. Our Atomic Force Microscope (AFM) products are optimized for research, product development and process control applications when visualization and measurement of nanometer-sized surface structure is critical. Pacific Nanotechnology offers high performance, easy to use, versatile AFM products. The new Nano-DST ${ }^{\mathrm{TM}}$ is the ultimate AFM research platform.

\author{
PANALYTICAL INC. \\ amec.info@panalytical.com \\ www.panalytical.com
}

Key Products: X-ray Spectrometers; X-ray Diffraction; X-ray Fluorescence PANalytical Inc. is the leading world supplier of analytical X-ray instrumentation and software for elemental analysis, phase characterization and small angle scattering. PANalytical has been providing X-ray instrumentation for over 50 years to nanomaterial, pharmaceutical, and materials research and process control applications. Our X-ray diffraction products are designed and engineered to supply our customers with solutions to solve complex problems such as thin film characterization; e.g., epitaxial, reflectivity and diffuse scattering, and determination of bulk material properties using the most advanced software algorithms for data collection, phase and structure determination. Additionally, our X-ray spectrometry systems provide elemental analysis for semiconductor and process control applications. Finally, our commitment to providing a customer based solution is exemplified by the largest and most dedicated customer support group in the X-ray business.

\section{PARK SYSTEMS INC.}

info@parkafm.com

www.parkafm.com

Key Products: AFM Products; AFM Mode Options

Park Systems serves its customers by providing a complete range of SPM solutions including AFM systems, options, and software, along with global service and support. Park Systems is a leading nanotechnology solutions partner for the most demanding imaging and measurement needs in research and industry. The company has an established reputation in the field stemming from its beginnings at Stanford University over 20 years ago. The innovative XE-Technology, which eliminates background curvature associated with conventional AFMs, has been widely acknowledged by major research institutions around the world. The latest developments from Park Systems include the XE-NSOM for diverse optical applications including NSOM and Raman spectroscopy and the XE-Bio for life science research applications.

\section{TED PELLA, INC.}

sales@tedpella.com

www.tedpella.com

Key Products: Vacuum Coaters; Calibration; Sample Preparation Supplies/Accessories

Ted Pella, Inc. offers a full range of compact versatile bench top vacuum coaters for thin film research and electron microscopy applications which can be equipped with high resolution thickness monitors and multi-angle rotary stages. New products are a full line of vacuum pumps and parts for research applications and small scale production. On display will also be a large selection of supplies, consumables, tools and sample preparation equipment for SEM, TEM, AFM, Raman light microscopy and nanotechnology.

\section{PHYSICAL ELECTRONICS \\ sales@phi.com} www.phi.com

Key Products: Scanning Auger; SIMS; XPS; ESCA; TOF-SIMS; Materials Analysis; Surface Analysis

Physical Electronics (PHI) is a subsidiary of ULVAC-PHI, the world's leading sup plier of UHV surface analysis instrumentation used for research and development of advanced materials in a number of high technology fields including: nanotechnology, microelectronics, storage media, bio-medical, and basic materials such as metals, polymers, and coatings. PHI's innovative XPS, AES, and SIMS technologies provide our customers with unique tools to solve challenging materials problems and accelerate the development of new materials and products. For additional information visit our website at www.phi.com 


\section{PHYSICS TODAY}

\section{www.physicstoday.org}

Key Products: Publications; Buyers Guide

Materials scientists can search $100+$ physics journals for the articles recently published in their field. Stop by to preview the new features at www. physicstoday.org, and pick up a free light-up pen! The new site accesses hundreds of physics jobs, an events calendar, and buyers' guide.

\section{PIEZOSYSTEM JENA, INC.}

usa@piezojena.com

www.piezojena.com

Key Products: Nanopositioning Systems; Piezo Stages; Microscope Stages

We are a world leading company in the development, design and engineering of piezo actuator based positioning systems for micro- and nanopositioning and nanoautomation. Piezosystem Jena is the exclusive US representative for SIOS interferometric equipment. We also manufacture multimode fiberoptic switches for fluorescence and spectrographic studies.

\section{PLASMA PROCESS GROUP, INC. sales@plasmaprocessgroup.com} www.plasmaprocessgroup.com

Key Products: lon Beam Samples; Ion Beam Power Supplies; Ion Beam Systems Plasma Process Group makes DC and RF ion beam sources, power supplies, systems, and components, ranging from replacement parts such as grids, to complete thin film systems. We repair and refurbish ion beam equipment, including lon Tech, and power supplies, and offer custom engineering services and support for unique applications.

\section{PLASMATERIALS, INC}

\section{info@plasmaterials.com}

www.plasmaterials.com

Key Products: Sputtering Targets; Backing Plates; Evaporation Materials

Plasmaterials, Inc. provides high purity Physical Vapor Deposition (PVD) materials in nearly every element, alloy, composition and component available on the periodic table. Products include sputtering targets, backing plates and other segments of the materials market including evaporation material, crucible liners and electron beam starter sources. In addition to backing plates, we also provide metallic bonding services. The bonding process utilizes a proprietary process for affixing the target directly to the backing plate using

low vapor pressure materials. These bonding materials provide the necessary mechanical strength, thermal and electrical conductivity while allowing differential expansion between the target and the backing plate. Backing plates for nearly all commercial available systems are usually in stock for immediate delivery. Customer designed backing plates can usually be provided within a short period of time. A full service company, Plasmaterials, Inc. can provide all of your deposition materials needs.

\section{PRINCETON SCIENTIFIC CORP. \\ info@princetonscientific.com \\ www.princetonscientific.com}

Key Products: High Purity Elements; Metal Single Crystals; Polishing \& Crystal Orientation Services; Optical, Laser \&

Opto-Electronic Components

Princeton Scientific Corp. offers various metal and oxide single crystals, like W, Mo, $\mathrm{Au}, \mathrm{SrTiO}_{3}, \mathrm{TiO}_{2}$ and $\mathrm{MgO}$, as well as a number of III-V materials such as $\mathrm{GaAs}, \mathrm{GaP}$, InSb, InAs, InP, and more. Cutting and polishing services are also provided. Also on display is a precision wire saw which allows for a very accurate cutting process and yields surfaces with almost "lapped" quality. Pulsed power supplies (square wave) for bipolar and unipolar applications in sputterand CVD processes will also be shown.
PVD PRODUCTS, INC.

sales@pvdproducts.com

www.pvdproducts.com

Key Products: Sputter Systems; Sputter Sources; Pulsed Laser Deposition Equipment

PVD Products sells a complete line of thin film deposition tools including magnetron sputtering, pulsed laser deposition, thermal and electron beam evaporation systems for both $R \& D$ and prototype production applications. We manufacture custom components such as magnetron sputter sources, substrate heaters, target manipulators, and optical trains and unique components for coated-conductor applications. PVD also provides thin film deposition, SEM, and EDS services.

\section{Q-SENSE, INC.}

info@q-sense.com

www.q-sense.com

Key Products: E4 System; E1 System; Sensor Crystals

Q-Sense is a Swedish-based company specializing in quantifying changes at various interfaces. Q-Sense develops and markets analysis instruments and complete measurement solutions for molecular interaction and absorption based on the unique and patented Quartz Crystal Microbalance with Dissipation Monitoring (QCM-D) technology. Our instruments are found in over 25 countries and citied in over 350 publications. Examples of applications include real time monitoring of DNA hybridization, several aspects of protein/lipid/cell/bacterial adsorption/adhesion, protein-protein interactions, cross-linking, and phage display.

\section{QUANTUM DESIGN, INC. \\ info@qdusa.com \\ www.qdusa.com}

Key Products: Physical Property and Magnetic Property Measurement Systems

Quantum Design is the leading manufacturer of automated material characterization systems for the physics, chemistry, and materials science research communities. These systems provide temperatures from $<0.4$ to $1000 \mathrm{~K}$ and magnet fields up to 16 tesla. The SQUID-based Magnetic Property Measurement System (MPMS) is the industry standard for ultra-sensitive magnetic measurements. The Physical Property Measurement System (PPMS) is an innovative device designed to provide a wide range of fully automated measurements, including: magnetometry (AC, DC, Torque, and VSM), electrical transport (AC, DC, Hall effect and critical current), thermal transport (thermal conductivity, Seebeck coefficient, thermopower), and heat capacity. Both systems can be supplied with an optional cyrocooler.

\section{RADIANT TECHNOLOGIES, INC.}

radiant@ferrodevices.com

www.ferrodevices.com

Key Product: Ferroelectric Testers; Ferroelectric Components; Educational Test Systems and Materials

Radiant Technologies introduces our new Precision Materials Analyzer familythe Precision Premier II, Precision LC, and RT66B which extends the precision, flexibility and ease of Radiant's testers into the megahertz measurement range. The Precision Family introduces $1 \mu$ ground hardware driven by Windows NT $4.0^{\mathrm{TM}}$ user interface, revolutionary software design that provides exceptional freedom to design, conduct, and review tasks associated with any materials experiment. Radiant has also introduced a new EDU research test systems designed to teach students about ferroelectric capacitors and sensors in a laboratory environment.

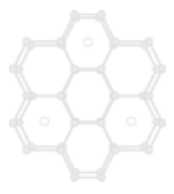


REFINING SYSTEMS, INC. www.refiningsystems.com

Key Products: Sputtering Targets; Evaporation Materials; Wires and Tubing Since 1986, Refining Systems, Inc. has been an industry leader in the manufacturing of metals and materials for science and industry. We manufacture custom-made sputtering targets, evaporation materials, crucibles rods, sheets, wires, foils, shots, tubing, discs and other items. Our product line has been tailored to meet the increasing needs of high-tech industries, research facilities, vacuum coating industries and other trades. Please stop by our booth to view our extensive product line.

\section{RENISHAW INC.}

\section{usa@renishaw.com}

www.renishaw.com

Renishaw Raman Microscopes provide chemical information at a spatial resolution of less than 1 micron. Renishaw's spectrometers perform from $244 \mathrm{~nm}$ to $830 \mathrm{~nm}$, analyze to within $10 \mathrm{~cm}^{-1}$ of the laser line and include direct 2-D Raman and photoluminescence imaging. Process and Forensic Raman Spectrometers interface options include optical, AFM and SEM microscopes.

\section{RESEARCH AND PVD MATERIALS CORPORATION rpvd.melvin@erols.com} www.pvdmaterials.com/index.html

Key Products: Sputtering Targets; Evaporation Sources; All Products for Physical Vapor Deposition

Research and PVD Materials Corporation manufactures a wide variety of highly characterized, high purity materials for the diverse and sophisticated requirements of the semiconductor, electronics, electro-optic and related research communities. Products from this single-quality source include but are not limited to sputtering targets, thin-film deposition materials, fabricated forms of specialty and exotic metals, alloys, ceramics, intermetallics, custom fabrications and "one off" components.

\section{RHK TECHNOLOGY, INC.}

Exhibiting within the NanoLinks Group

info@rhk-tech.com

www.rhk-tech.com

Key Products: SPM Universal Controls; UHV STM; UHV AFM/STM

Imaging the Future of Nanoscience: RHK is the chosen company for fundamental science at the atomic scale. Our UHV STM, AFM, 4-Probe systems, controllers, and electronics are engineered for the advanced researcher but comfortably systemized for the first-time buyer. To choose RHK means to experience peak performance, scalability, compatibility, and value. Celebrating 20 years of commitment to customer and quality, we partner with the researcher to support our products over a lifetime of experimental success.

\section{RIGAKU AMERICAS CORPORATION info@rigaku.com www.rigaku.com}

Key Products: X-ray Diffraction Systems; Small Angle X-ray Scattering Systems Rigaku provides the world's most complete line of X-ray diffraction and X-ray fluorescence instruments and components, including benchtop XRD and XRF systems, X-ray optics and detectors, the Saturn and SCXmini CCD-based single crystal diffractometers for small molecule crystallography, the Ultima IV and SmartLab ${ }^{\oplus}$ multi-purpose diffractometers with SAXS and in-plane capabilities, and the ZSX Primus series of high-powered WDXRF spectrometers with mapping capabilities, in either tube-above or tube-below configurations.

\section{ROYAL SOCIETY OF CHEMISTRY \\ rscpublishing@rsc.org \\ www.rsc.org}

Key Products: Journals; Books

The largest organisation in Europe for advancing the chemical sciences, with 44,000 members and an internationally acclaimed publishing business. Visit ou booth for the latest publishing developments including the first weekly materials journal, Journal of Materials Chemistry, number one journal Soft Matter, and new journal Energy \& Environmental Science. Discover award-winning RSC Prospect and our top selling book collection, including the latest edition of Nanochemistry: A Chemical Approach to Nanomaterials by Ozin \& Arsenault.

\section{RUBICON TECHNOLOGY, INC. \\ sales@rubicon-es2.com \\ www.rubicon-es2.com}

Key Products: Sapphire Substrates; Single Crystal Windows; Single Crystal Lenses, Rods, Tubes

Rubicon Technology is an advanced electronic materials provider that is a leader in developing, manufacturing and marketing sapphire substrates and other innovative crystalline products for Light-Emitting Diodes (LED), radio frequency integrated circuits (RFICs), blue laser diodes, optoelectronics and other optical applications. We provide our products for the solid state lighting, semiconductor electronics, consumer electronics as well as aerospace, sensor and medical markets.

\section{SEKI TECHNOTRON CORPORATION}

www.sekicvdsolutions.com

Key Products: Plasma CVD Systems; Hot-Filament CVD Systems; Microwave Plasma CVD Systems

Seki Technotron is the leading manufacturer of Microwave Plasma CVD Systems and the exclusive worldwide supplier of sp3 Diamond Technologies' Hot Filament CVD Systems. Our Microwave Plasma CVD systems are designed for high growth rate, high quality diamond films, single-crystal diamond, carbon nanotubes and advanced material research, for deposition areas up to $200 \mathrm{~mm}$ and power levels from 1.5 to $100 \mathrm{~kW}$ depending on required process and growth rates. The sp3 Hot filament CVD system provides highly uniform deposition over 14-sq. in. smooth ultra nanocrystalline and facetted diamond films for electronics, tools, and wear part coating applications. We work closely with our customers to select the CVD system and process solution most suited for the intended R\&D and production applications. Please visit our website at www.sekicvdsolutions.com.

\section{SHIMADZU SCIENTIFIC INSTRUMENTS, INC. \\ webmaster@shimadzu.com}

www.shimadzu.com

Key Products: EDX-720 Energy Dispersive X-Ray Instrument; AGX Universal Testing Instrument

Shimadzu's Energy Dispersive X-ray Fluorescence Spectrometer, EDX 720, is an industry leader in the field of trace and rapid elemental analysis. The EDX series can be used for compliance with regulations (e.g., RoHS and ELV), quantitative analysis, and monitoring processes. For example, the EDX series can rapidly screen for elements such as $\mathrm{Pb}, \mathrm{Cd}, \mathrm{Hg}$, as well as $\mathrm{PBB}$ and $\mathrm{PBDE}$, and $\mathrm{Cr} 6+$, which are regulated by the RoHS directive. See our Universal Testing machine as well.

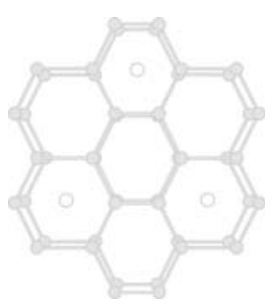


SIGMA-ALDRICH CORPORATION matsci@sial.com

www.sigma-aldrich.com/matsci

MRS

MRS

AFFILIATE

AFFILIATE

Key Products: 3D Nano \& Micro Structures; Nanoscale Surface Modification; Biomaterials \& Alternative Energy

Sigma-Aldrich ${ }^{\circledast}$ is a leading high-technology company. Through our Materials Chemistry Centers of Excellence in research and manufacturing we develop advanced, enabling materials for your micro/nanoelectronics, alternative energy, organic electronics, nanotechnology and related materials science and engineering applications. Specialties include self-assembly materials, thin-film precursors, organic semiconductors, nanomaterials, crystal growth materials, metals and alloys, fuel cell materials, electronic grade dyes, specialty monomers and cGMP grade polymers. Visit our Web site at sigma-aldrich. com/matsci or contact us at matsci@sial.com for applications data, tutorials and product listings.

\section{SILICON SENSE, INC.}

www.siliconsense.com

Key Products: Silicon Wafers; Foundry Services

Silicon Sense Incorporated is a world-class supplier of high quality substrates and custom foundry services. We supply silicon wafers from 2 " to 8 " diameter as well as oxide, nitride, photolithography, and dicing services. Our extensive resources allow us to meet all of your production needs from product development and prototyping to small, medium and large volumes. Ask us about the University discount!

\section{SMALL TIMES}

www.smalltimes.com

Small Times is the leading global media source for micro and nanotechnology news, information and analysis. Recognized as the leading industry publication, Small Times magazine reaches 27,000 qualified decision makers. SmallTimes.com, the most comprehensive electronic source for international news covering the commercialization of micro and nanotechnology receives in excess of 100,000 page views per month. The weekly opt-in newsletter, Small Times Direct reaches more than 22,000 subscribers throughout the world.

\section{SOUTHWEST NANOTECHNOLOGIES INC.}

\section{info@swentnano.com}

www.swentnano.com

\section{Key Products: Single-wall Carbon Nanotubes}

Located in Norman, Oklahoma, SouthWest NanoTechnologies Inc. (SWeNT) is a leading manufacturer of single-wall carbon nanotubes. SWeNT produces three lines of carbon nanotube products using the scalable, low-cost CoMoCAT ${ }^{\oplus}$ process, which ensures consistent high quality and the flexibility to provide tailored material. In June 2008, SWeNT moved into a new manufacturing facility, where its single-wall carbon nanotube production capability increased 100-fold at one-tenth the cost. The company was founded in 2001 to commercialize nanotube technology developed at the University of Oklahoma by Daniel Resasco, a professor of chemical engineering and worldrenowned expert in the fields of single-wall carbon nanotubes and catalysis.

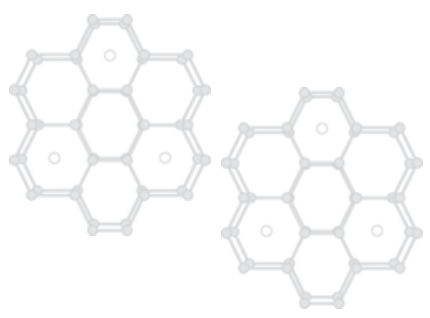

SPECS SCIENTIFIC INSTRUMENTS, INC. support@specs.com www.specs.com

Key Products: XPS; MBE; OLED

Bio and Nano Technology, NanoAnalysis, NanoManipulation, NanoSpectrocopy, NanoMotion, Digital Robotics, GC/MS LC/MS, Surface Analysis Instruments and Materials Deposition Equipment for XPS, STM, AFM, LT-STM, MBE, CVD, ALD, OLED, PLD, 3D Laser Atom Probe, LEED, EELS, UPS, Auger, ESCA, SIMS, SNMS, PEEM, LEEM, KELVIN-Probe, RHEED, E-Beam Evaporation, Effusion Cells, Plasma Atom/lon Sources, Magnetron Sputter Deposition, Bio-Organic Injectors, Beamlines, Monochromators, and Synchrotron Equipment.

SPECS USA CORP

sales@specsus.com www.specsinstruments.com

Key Products: Electron Spectrometers; SPM; Deposition Equipment

SPECS manufactures cutting-edge systems and components for surface analysis in UHV, based on methods like XPS, UPS, AES, ISS, STM, LEEM/PEEM LEED, SIMS, SNMS and HREELS. We offer a variety of sources for deposition, excitation and charge neutralization as well as analyzers, monochromators and research microscopes like LEEM and STM. A strong focus of our work is on customized systems combining thin film preparation (MBE) with spectroscopic and microscopic options.

SPEX SAMPLEPREP LLC

sampleprep@spexcsp.com www.spexcsp.com

Key Products: Mixer/Mills; Katanax Automated Electric Fluxers; Freezer/Mills SPEX SamplePrep provides products for grinding and pulverizing even the toughest samples. These include high-energy ball mills, swing mills, and cryogenic mills. Over the past few decades, the SPEX SamplePrep Mixer/Mill, widely known as the "SPEX Mill," has become the industry standard for mechanical alloying applications. The high energy of the milling action, and the durability of the motor, allow running for extended periods. We're also known for our Freezer/Mill, the only "True Cryogenic Mill."

\section{SPI SUPPLIES \\ Division of Structure Probe, Inc. \\ info@2spi.com \\ www.2spi.com}

Key Products: Electron Microscopy Supplies; Sputter Coaters; Plasma Etchers

SPI Supplies will be featuring its newest products including the OPC Osmium Plasma Coater for "zero grain size" coating, Plasma Prep ${ }^{T M} X$ parallel plate (anisotropic) plasma etcher (for no undercutting), MACO ${ }^{\circledR}$ TEM film, and the Secador ${ }^{\oplus}$ automatically regenerating desiccant module for sample storage. Also on display will be the popular line of SPI Module ${ }^{\mathrm{TM}}$ SEM/EDS coaters and the Plasma Prep ${ }^{\mathrm{TM}}$ II plasma etcher. Visit www.2spi.com to learn more about these innovative new products or to place an order using the on-line shopping cart.

\section{SPIRE BIOMEDICAL, INC. \\ biosales@spirecorp.com \\ www.biomedical.com}

Key Products: Biomaterials; Thin Films

Spire Biomedical is a leading provider of advanced surface modification services for implantable medical devices and biomedical instruments. The company offers customized biocompatible metal and ceramic coatings and surface treatments to meet a wide range of needs including, wear and friction reduction, enhanced bone in-growth, anti-microbial property, radiopacity, electrical conduction and insulation, hydrophilicity, surface functionalization, and surface engineering on the nanoscale. 


\section{SPIRE SEMICONDUCTOR, LLC} www.spiresemi.com

Key Products: Multi Junction Photovoltaic Solar Cells; Red LEDs; Blue/Green Lasers

Spire Semiconductor is a pure-play III-V and II-VI compound semiconductor foundry. We offer design, development and manufacturing services for the concentrated photovoltaic, defense, telecommunication and biomedical markets. With over 25 years experience in epitaxial growth and device processing we offer our clients a shorter time to market, a higher degree of product differentiation, an ability to rapidly ramp to high-volume manufacturing and an overall edge in the marketplace. Spire Semiconductor offers close customer collaboration with our scientists and engineers and we ensure the protection and confidentiality of our customer's intellectual property.

\section{SPRINGER}

exhibits-ny@springer.com

www.springer.com

Key Products: Books; Journals; Periodicals

Springer is one of the world-leaders in engineering book publishing, boasting a broad range of subject matter, and a history of working with the most prestigious scholars in the field. Additionally, Springer publishes an astute collection of Journals, with a track record of generating the latest sought after content. For additional information about all our engineering publications, please stop by our booth, or visit us at Springer.com.

\section{STAIB INSTRUMENTS, INC.}

\section{staib-us@staibinstruments.com}

www.staibinstruments.com

Key Products: RHEED; Spectrometer; Surface Analysis

STAIB designs and manufactures innovative, high performance, reliable instruments for in-situ material analysis including: a full range of Electron Guns for analytical surface studies (flood, microfocus, general purpose, low energy, nano-focus); RHEED systems (new in CVD-PLD-PVD environments) to study structure and quality of thin films; CMA energy spectrometers (Auger, SAM, XPS, and UPS) for analytical surface studies; SEM using our micro-focus guns; Photo-Electron Emission Microscopes (PEEM); ESCA; X-ray Sources; and Multi-Technique Surface Analysis Chambers.

\section{STREM CHEMICALS, INC.}

info@strem.com

www.strem.com
MRS

CORPORATE

AFFILIATE
Key Products: Chemicals; Nanomaterials; CVD and ALD Precursors

Strem Chemicals manufactures and markets a wide variety of metals, inorganics and organometallics for research and commercial scale production for the materials science community including a wide range of MOCVD, CVD and ALD precursors and Nanomaterials (nanoclusters, nanocolloids, nanoparticles, nanopowders, nanomagnetic fluids). We also perform custom synthesis work and provide a variety of catalysts and ligands for organic synthesis, rare-earth and electronic grade chemicals for ultra high-purity needs and ionic liquids. Ask for our NEW Catalog 22 (2008-2010) of over 4000 products.

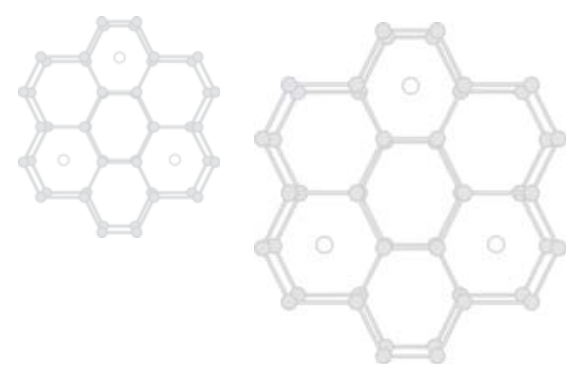

SUPER CONDUCTOR MATERIALS, INC.

sales@scm-inc.com

www.scm-inc.com

Key Products: Sputtering Targets; Evaporation Materials; Crucible Liners

Serving the vacuum Industry since the 1980s, SCM, Inc. uses inert hot pressing, vacuum hot pressing, and induction melting to produce targets. Sputtering targets and evaporation materials are available in various purities from $99.9 \%$ to $99.9999 \%$. Ceramic materials are produced using an advanced hot pressing technique, which yields targets with densities approaching theoretical, much greater than other ordinary techniques. It also provides excellent homogeneity, which ensures repeatable use. Crucible inserts for all the major E-beam systems are available. For all your magnetic, optical, LCD, ferroelectric, and microelectronic material needs, please visit our website at www.scm-inc.com.

\section{SURFACE SYSTEMS \& TECHNOLOGIES GMBH \& CO. KG info@surface-tec.com www.surface-tec.com}

Key Products: PLD-Workstation; Laser MBE Systems; Laser Heating Stages Since 1994, SURFACE develops and sells PLD systems. The PLD-Workstation, a very compact "all-in-one frame" system, includes all of the necessary process components in only one rack. The modular laser MBE cluster tool system can be expanded from a single chamber to a multi chamber, multi process system. Advanced accessories like substrate laser heaters or high pressure RHEED systems were developed. All SURFACE PLD systems use the advanced "Plume Master" automation software. NEW from SURFACE: Laser sample heater for nanoindentation systems with a temperature range up to $600^{\circ} \mathrm{C}$.

\section{SUSTAINABLE CARBON NANOTECHNOLOGY \& ENGINEERING (SCNTE) info@scnte.com} www.scnte.com

Key Products: Carbon Nanotubes; Carbon Nanorods; Catalyst; Battery; Fuel Cell; Sensor

Sustainable Carbon Nanotechnology \& Engineering (SCNTE) is a materials manufacturing company that specializes in electrochemical grade carbon nanotubes and related structures. SCNTE has pioneered a non-catalytic growth process that allows the commercial production of carbon nanotubes and related structure for battery, sensor, and fuel cell applications. SCNTE produces $99.9 \%$ crystalline nano carbon with extremely fast electron transfer rates and extremely high edge plane character.

\section{SVT ASSOCIATES, INC.}

\section{info@svta.com}

www.svta.com

Key Products: MBE, ALD, In-Situ Monitoring Equipment

SVT Associates offers a full range of MBE, thin-film deposition, in-situ process monitoring, and related UHV equipment for advanced materials. Since 1993, we have designed and delivered tailored solutions for emerging materials through MBE, ALD, PLD, and UHV deposition equipment innovations. In addition, internally developed in-situ process monitoring tools provide the highest level of accuracy and precision for closed loop control of temperature, deposition rate, thickness, and stress. By having the industry's most advanced MBE and thin film applications lab, SVT ensures all products are well suited for each application and include material performance guarantees. Epiwafer and advanced device manufacturing services are also available for $\mathrm{GaN}$ and $\mathrm{ZnO}$ related materials. Please contact SVT for more information. 
SYCON INSTRUMENTS, INC.

info@sycon.com

www.sycon.com

Key Products: Thin Film Instrumentation; Sensors; Accessories

Sycon Instruments, Inc. is a manufacturer of Thin Film Deposition Monitors and Controllers utilizing the quartz crystal sensing techniques. These products include the STC-2002 deposition controller, STM-2XM 2 Channel Thickness Rate Monitor, the STC-2000A deposition controller for the budget minded. The EBS-530, E-Beam Sweep Control for Electron Beam Sweep Control. The STM-1 Monitor with integrated oscillator for use with Lab View on your PC. The SRT-422 E-Beam Source Indexer. The T-3000 Deposition Power Supply. The VSO-100 In-Vacuum sensor oscillator and a complete line of sensors, crystals and feedthroughs. All products available for quick delivery all over the world.

\section{TAYLOR \& FRANCIS GROUP LLC-CRC PRESS orders@crcpress.com \\ www.crcpress.com}

Key Products: Books; Journals; NetBase Products

Take your research skills to the next level with Taylor and Francis Group/CRC Press, leading publisher of technical references and textbooks in Materials Science. Visit our booth to see the latest books in Polymers, Ceramics, Metals, Composites, Biomaterials, Electronic Materials, and Nanomaterials, and get $15-25 \%$ off an authoritative range of titles.

\section{TCI AMERICA}

sales@tciamerica.com

www.tciamerica.com

Key Products: Specialty Organic Chemicals; Glycochemistry Reagents; Glycobiology Reagents; Custom Synthesis; Pharmaceutical Intermediates; Columns for HPLC, GC,IC and NMR Tubes

$\mathrm{TCl}$ America manufactures laboratory chemicals, provides custom synthesis and offers contract research services for pharmaceutical, cosmetic, electronic, chemical, and biotechnology researchers. 2008-2009 Laboratory Chemicals Catalog lists 20,000+ products with over 1800 new items. Reagent Guide, Bulk and Glyco-Chemistry \& Biology Catalogs are also available. Manufacturing capabilities include multi-step synthesis and continuous production from milli to ton scale. Modern facilities can provide cGMP manufacturing and are registered with the FDA. Visit our website today: www.tciamerica.com.

\section{THE MELLEN COMPANY, INC. \\ info@mellencompany.com}

www.mellencompany.com

Key Products: Laboratory Furnaces; Custom Furnaces; Controls and Crystal Growth Systems

The Mellen Company manufactures high temperature furnaces for research and production. Mellen high temperature furnaces range from 200 degrees $C$ to 2000 degrees $C$. Sizes range from very small desktop models to very large processing floor models. Mellen specializes in research and prototypes for special processes, in addition to our furnace standard line. Mellen will have several small furnaces on display as well as furnace accessories.
THERMAL TECHNOLOGY LLC

www.thermaltechnologyinc.com

Key Products: Spark Plasma Sintering Technology; High Temp Vacuum and Controlled Atmosphere Furnaces; High Temp Crystal Growing Systems

Thermal Technology LLC is a US based high temperature equipment engineering and manufacturing company. Thermal Technology LLC designs and manufactures standard and custom-designed spark plasma sintering (SPS) systems, crystal growing systems, arc furnaces, and high temperature vacuum and controlled atmosphere furnaces (lab and production systems). This incredibly broad product line with its associated engineering and applications skills make Thermal Technology LLC one of the best resources in the world for your high temperature applications. THINK "SOLUTIONS!"

\section{THERMIONICS VACUUM PRODUCTS \\ sales@thermionicscorp.com \\ www.thermionics.com}

Key Products: Sample Handling; Thin Film Deposition Equipment; Valves

Manufactures vacuum components, systems and accessories for production and research applications including: our new line of compact manipulators; our new ICR 1500 cc capacity eGun $^{\mathrm{TM}}$; our RC series of $3 \mathrm{~kW}$ e-Guns ${ }^{\mathrm{TM}}$; HC series e-Guns ${ }^{\mathrm{TM}}$ with dual filament capability for demanding production coating applications; PyraFlat ${ }^{\mathrm{TM}}$ rectangular flanges and waveguides; TriBond ${ }^{\mathrm{TM}}$ bi- $^{-}$ metallic flanges and fittings; gate and poppet valves; sample handling and transfer systems; ion pumps; maTChed ${ }^{\mathrm{TM}}$ thermocouple gauges; mechanical, electrical and fluid feedthroughs; and materials and surface science systems.

\section{THERMO SCIENTIFIC \\ analyze@thermo.com}

www.thermo.com

Key Products: FT-IR; Raman; UV-Visible; X-ray Microanalysis; X-ray Surface Analysis

Thermo Scientific, part of Thermo Fisher Scientific Inc., provides world-class solutions for materials research. These include high performance FT-IR, Raman and UV-Visible spectrometers for use in research and development. Our EDS X-Ray microanalysis system offers complete phase-based analysis of the sample at the push of a button. Spectral imaging-based microanalysis eliminates user bias. Our XPS spectrometers are a staple in materials characterization and are useful tools for the development of advanced bio-medical surfaces and nano-materials.

TREK, INC.

sales@trekinc.com

www.trekinc.com

Key Products: High-Voltage Amplifiers; Electrostatic Voltmeters; Charge Decay Measurement

Trek, Inc. designs and manufactures a range of electrostatic measurement and high-voltage solutions for applications in Materials Research. Trek's HighVoltage Amplifiers provide high slew rates, accuracy and full four-quadrant operation, making them ideal for research in microfluidics, piezoelectric driving/control, ferroelectric characterization, laser modulation, MEMS, material poling, electrorheological fluids, electroactive polymers, electrophoresis, and electrospinning. TREK's Electrostatic Voltmeters provide noncontacting or contacting surface voltage measurements with sensitivities in the millivolt range. Surface Resistance Meters are also offered.

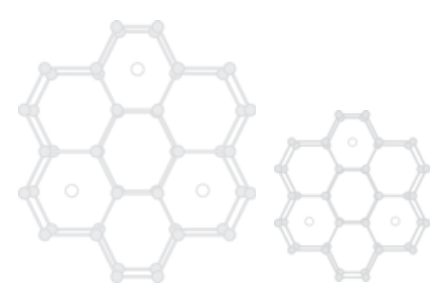


TRION TECHNOLOGY, INC.

\section{info@triontech.com}

www.triontech.com

\section{Key Products: RIE/ICP; PECVD; Strip}

Trion manufactures a wide variety of Plasma Etch, Strip and Deposition Equipment for the Failure Analysis, Compound Semiconductor, MEMS, OptoElectronic and other markets. Our products feature the smallest footprint and lowest cost systems in the industry with proven production reliability. The tools process up to $300 \mathrm{~mm}$ wafers, wafer segments, packaged devices and small electronic parts. Complete process support, including recipes. Processes include silicon, quartz, GaAs, InP and GaN.

\section{ULVAC TECHNOLOGIES, INC. \\ sales@us.ulvac.com \\ www.ulvac.com}

MRS
CORPORATE

Key Products: Seebeck Measuring Equipment; Annealing Furnace; Vacuum Systems; Pumps; Leak Detectors

ULVAC-RIKO specializes in thermo-physical property measurement systems. Products include high temperature IR gold reflector furnaces, a furnace hotstage optical microscope, a programmable tabletop RTA furnace, Laser Flash unit for thermal conductivity, LaserPIT for in-plane thermal diffusivity of thin sheet or thin films, and a Seebeck coefficient and electrical resistance-measuring instrument. ULVAC-RIKO is a division of ULVAC, an international corporation that provides systems and components used in manufacturing and research applications requiring vacuum technology.

\section{UNIVERSITY OF LOUISVILLE/NAUGANEEDLES LLC \\ www.uofl.edu \\ www.nauganeedles.com}

Key Products: Custom-made Atomic Force Microscope Probes

UofL announces the availability of ultra-high aspect scanning microscopy probes for evaluation and purchase. Flexible constant diameter metallic nanoneedles (5-100 microns long and 60-600 nm diameter) can be selectively grown and oriented on AFM, STM and NSOM probes, tapered glass capillaries, micromachined surfaces and sidewalls, and even on quartz tuning forks. Visit our booth to learn how these novel probes can enhance your SPM measurements.

\section{VARIAN, INC.}

\section{vtl.customer.service@varianinc.com}

www.varianinc.com/vacuum

Key Products: FT-IR; UV-VIS-NIR; Vacuum Technologies

Varian, Inc. is a world leader in providing total vacuum solutions. Product offerings include primary, high and ultra-high vacuum pumps, vacuum gauges, valves and fittings, and leak detectors for all applications. Varian offers unique expertise in applications, support, and system design to integrate these superior components into optimized vacuum solutions.

\section{VAT, INC.}

us@vatvalve.com

www.vatvalve.com

Key Products: Control Valves; Vacuum Valves

VAT is the worldwide leader in vacuum valve technology. VAT will have on display the following valves: gate, pendulum, isolation, butterfly, control, angle, all-metal. VAT sales engineers are available to assist you with your vacuum valve requirements in applications such as: CVD, coating, pump isolation, laser, high energy physics, semiconductor, load locks, beam lines, and many more.

\author{
VEECO INSTRUMENTS INC. \\ info@veeco.com \\ www.veeco.com
}

Key Products: Atomic Force Microscopes; Optical Profilers; Stylus Profilers; Epitaxial Equipment

Veeco's complementary thin-film technologies, metrology tools, and world class probes facility make it the industry's most complete equipment supplier Our scanning probe microscopes and optical/stylus profilometers are used in research facilities and industrial settings for materials sciences, polymer studies, thin films, MEMS/NEMS, biomaterials and life sciences. We are also the only company offering both MBE and MOCVD technologies for the research, development and production of compound semiconductor devices. Veeco's performance fuels our customers' success.

\section{VG SCIENTA, INC.}

usasales@vgscienta.com

www.vgscienta.com

Key Products: Surface Science Systems; UHV Components; UHV Systems

The new VG Scienta is the world's premiere supplier of vacuum components, surface analysis instruments, and UHV systems to industry, research and development firms, and the scientific community. VG Scienta remains at the cutting edge of science with over 30 years experience in HV and UHV technology.

\section{VIRGINIA SEMICONDUCTOR, INC. \\ sales@virginiasemi.com}

www.virginiasemi.com

Key Products: Silicon Wafers; SOI Wafers; Ultrathin Wafers

Virginia Semiconductor, Inc. is a leading manufacturer of prime single crystal silicon substrates. Offering production quantities of 2- to 6-in. diameter silicon and small quantities of 1 - to 6 -in. diameter customer silicon substrates. We also offer custom 2- to 6-in. SOl substrates.

\section{WAFER WORLD INC.}

sales@waferworld.com

www.waferworld.com

Key Products: Silicon Wafers; SO

Manufacturer of semiconductor materials in Silicon ( $F z, C z$, Low TTV, Thick Slabs, Oxide, MEMS Thin, EPI, SOI); Germanium; III-V Compounds (GaAs, InP $\mathrm{GaP}, \mathrm{GaSb}, \mathrm{GaN}$, InSb, InAs) in reclaim, test, prime and two-sided polished surfaces; Optical Materials (Quartz, Ge, ZnSe, ZnS, Sapphire); Fiber Optical Materials ( $\left.\mathrm{LiNbO}_{3}, \mathrm{LiTaO}_{3}, \mathrm{CaCO}_{3}, \mathrm{TiO}_{2}, \mathrm{YVO}_{4}, \mathrm{YAG}, \mathrm{Gd}_{3} \mathrm{Ga}_{5} \mathrm{O}_{12}\right)$; and Superconductor Materials (MgO, LSAT, $\mathrm{LaAlO}_{3}, \mathrm{SrTiO}_{3}, \mathrm{SrLaAlO}_{4}, \mathrm{KTaO}_{3}$, $\mathrm{MgAl}_{2} \mathrm{O}_{4}$ ). Many stock and custom wafers available. Clean room packaging, equipment, consulting available. On Line Shopping Cart 24-hours a day!

WILEY BLACKWELL

info@wiley.com

www.wiley.com

Key Products: Books; Journals; Databases

Wiley-Blackwell publishes for the scientific community, scientific societies, and students worldwide. Wiley-Blackwell announces its new publishing partnership with The American Ceramic Society, including technical publications on ceramics, ceramic engineering, glasses, composites, crystallization, abrasives, cements, whitewares, and advanced ceramics. New Wiley-Blackwell books include Polarized Light in Liquid Crystals and Polymers, Materials Processing During Casting, and Molecular Semiconductors: An Introduction. Wiley-Blackwell is also the publisher of high-quality journals in Materials Sciences, e.g. Advanced Materials, Advanced Functional Materials, and Small. 
WILLIAMS ADVANCED MATERIALS

ceracinfo@beminc.com

www.williams-adv.com

www.cerac.com

Key Products: Specialty Inorganic Chemicals; Evaporation Materials; Sputtering Targets

CERAC's Specialty Inorganic Chemicals are used in the manufacture of semiconductor substrate precursors, pacemaker batteries, medical detector devices, phosphors, catalysts and temperature resistant aerospace coatings. CERAC is also developing new inorganic chemicals and PVD products for thin-film solar cells and other precision optical applications. From small specialty R\&D materials to scale up bulk chemical production, CERAC meets the challenge in developing new Inorganic Chemicals and PVD materials for your emerging application.

\section{WITEC INSTRUMENTS CORP.}

Exhibiting within the NanoLinks Group

info@witec-instruments.com

www.witec-instruments.com

Key Products: Confocal Microscopy; Scanning Near-Field; Raman AFM

WITec is a manufacturer of high-resolution optical and scanning probe microscopy solutions for scientific and industrial applications. A modula product line allows the combination of different microscopy techniques such as Raman, NSOM or AFM in one single instrument for flexible analyses of optical, chemical and structural properties of a sample. WITec headquarters and production facilities are based in UIm, Germany. WITec's US sales office, WITec Instruments Corp., is located in Savoy, IL.

\section{J.A. WOOLLAM COMPANY, INC.}

sales@jawoollam.com

www.jawoollam.com

Key Products: Spectroscopic Ellipsometers; Measurement Services

Spectroscopic ellipsometers for non-destructive materials characterization: multi-layer thickness, optical constants, growth and etch rates, composition and more. Offering the widest spectral ranges available: vacuum ultraviolet to the far infrared (142 $\mathrm{nm}$ to 33 microns) to meet all your metrology needs.

\section{X-RAY OPTICAL SYSTEMS, INC.}

info@xos.com

www.xos.com

Key Products: Polycapillary Optics; Doubly-curved Crystal; X-Beam-X-ray Source with Optics

XOS manufactures $x$-ray optics and beam systems. The company's design, manufacture, and characterization capabilities of polycapillary, monocapillary and doubly curved crystal optics, enables a range of focusing and collimating lens options. The product line of polychromatic and monochromatic X-Beams provides an optimized integration of $\mathrm{x}$-ray optics and sources. Applications include texture, stress, and phase ID, as well as film thickness and composition measurements. XOS optics are also used in fluorescence collection in EDS and WDS micro beam analysis.

\section{XEI SCIENTIFIC, INC. \\ info@evactron.com \\ www.evactron.com}

Key Products: Anticontaminators; RF Plasma Cleaners

XEl was founded in 1991 to make and sell anticontamination systems for the Electron Microscope community. The EVACTRON Anticontaminator, an RF plasma activated cleaning system, was introduced in 1999 to provide a faster and more complete cleaning process. XEI Scientific solves hydrocarbon contamination problems in Electron Microscopes and other high vacuum systems by RF plasma (glow discharge) cleaning with EVACTRON ${ }^{\circledR}$ plasma activated oxidation using air as the oxygen source. The Evactron ${ }^{\circledast}$ anticontamination system produces oxygen radicals for a fast, chemically reactive, oil and hydrocarbon removal process that is safe for most surfaces. Over 200 Evactron Anticontaminators have been installed worldwide.

\section{ZYGO CORPORATION \\ inquire@zygo.com}

www.zygo.com

Key Products: Optical Systems; Optics

Zygo Corporation is a worldwide developer and supplier of high-performance metrology instruments and systems, high-precision optics, optical assemblies, and automation for the semiconductor and industrial markets providing productivity and yield improvement solutions for manufacturers of precision components.

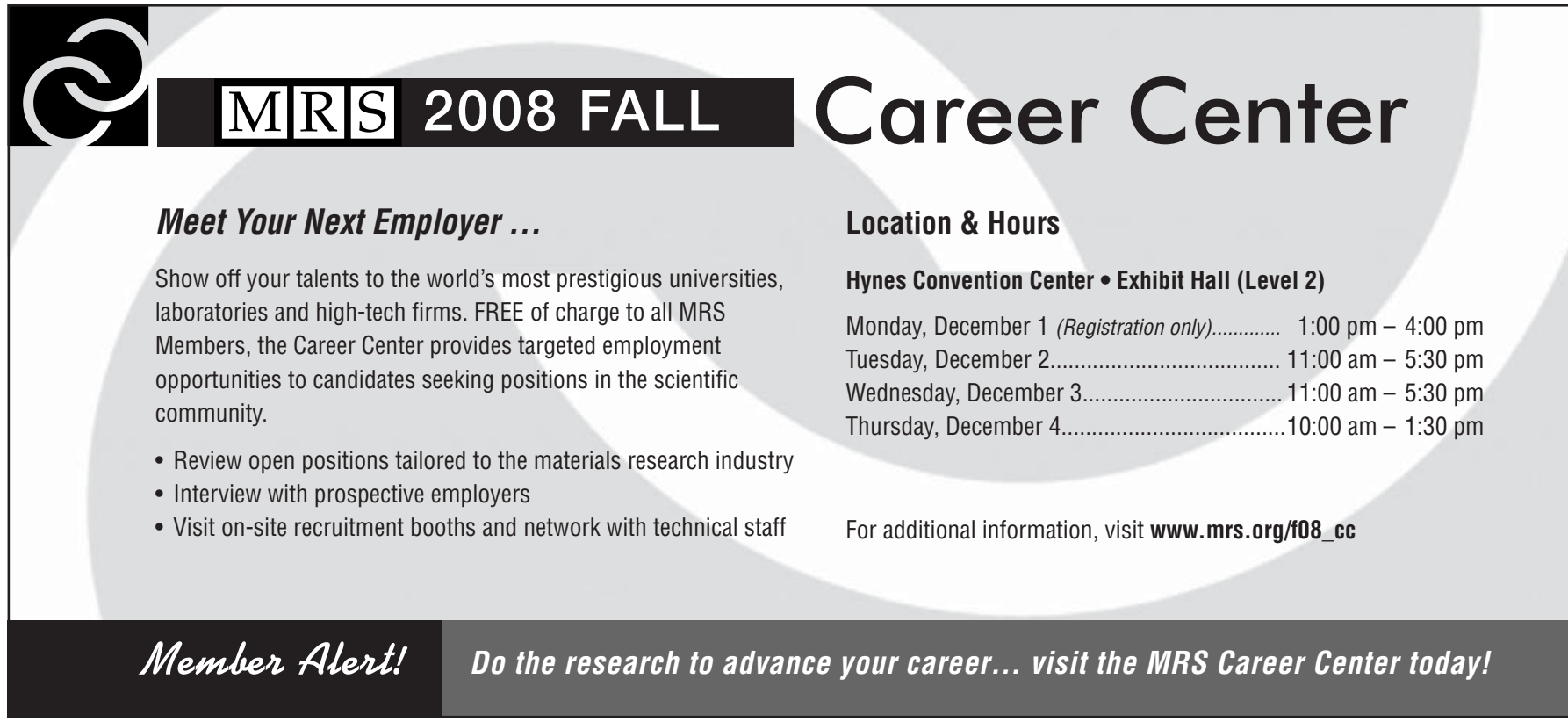

